San Jose State University

SJSU ScholarWorks

Master's Theses

Master's Theses and Graduate Research

1993

\title{
Performance of normal listeners on a digitally time-compressed version of the Northwestern University auditory test no. 6
}

Debra L. Salamon

San Jose State University

Follow this and additional works at: https://scholarworks.sjsu.edu/etd_theses

\section{Recommended Citation}

Salamon, Debra L., "Performance of normal listeners on a digitally time-compressed version of the Northwestern University auditory test no. 6" (1993). Master's Theses. 581.

DOI: https://doi.org/10.31979/etd.cux6-59gn

https://scholarworks.sjsu.edu/etd_theses/581

This Thesis is brought to you for free and open access by the Master's Theses and Graduate Research at SJSU ScholarWorks. It has been accepted for inclusion in Master's Theses by an authorized administrator of SJSU ScholarWorks. For more information, please contact scholarworks@sjsu.edu. 


\section{INFORMATION TO USERS}

This manuscript has been reproduced from the microfilm master. UMI films the text directly from the original or copy submitted. Thus, some thesis and dissertation copies are in typewriter face, while others may be from any type of computer printer.

The quality of this reproduction is dependent upon the quality of the copy submitted. Broken or indistinct print, colored or poor quality illustrations and photographs, print bleedthrough, substandard margins, and improper alignment can adversely affect reproduction.

In the unlikely event that the author did not send UMI a complete manuscript and there are missing pages, these will be noted. Also, if unauthorized copyright material had to be removed, a note wiil indicate the deletion.

Oversize materials (e.g., maps, drawings, charts) are reproduced by sectioning the original, beginning at the upper left-hand corner and continuing from left to right in equal sections with small overlaps. Each original is also photographed in one exposure and is included in reduced form at the back of the book.

Photographs included in the original manuscript have been reproduced xerographically in this copy. Higher quality 6 " $\mathrm{x} 9$ " black and white photographic prints are available for any photographs or illustrations appearing in this copy for an additional charge. Contact UMI directly to order.

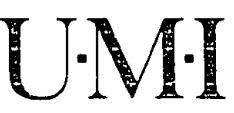

University Microfilms Internatıonal A Bell \& Howell Information Company 300 North Zeeb Road. Ann Arbor, MI 48106-1346 USA

$313: 761-4700 \quad 800 / 521-0600$ 

Performance of normal listeners on a digitally time-compressed version of the Northwestern University Auditory Test No. 6

Salamon, Debra Lyn, M.A.

San Jose State University, 1993 

PERFORMANCE OF NORMAL LISTENERS ON A DIGITALLY TIME-COMPRESSED VERSION OF THE NORTHWESTERN UNIVERSITY AUDITORY TEST NO. 6 .

\author{
A Thesis \\ Presented to \\ The Faculty of the Division of \\ Special Education and Rehabilitative Services \\ Program in Communication Disorders and Sciences \\ San Jose State University
}

\author{
In Partial Fulfillment \\ of the Requirements for the Degree \\ Master of Arts
}

By

Debra L. Salamon

May, 1993 
APPROVED FOR THE DIVISION OF SPECIAL EDUCATION AND REHABILITATIVE SERVICES PROGRAM IN

COMMUNICATION DISORDERS AND SCIENCES

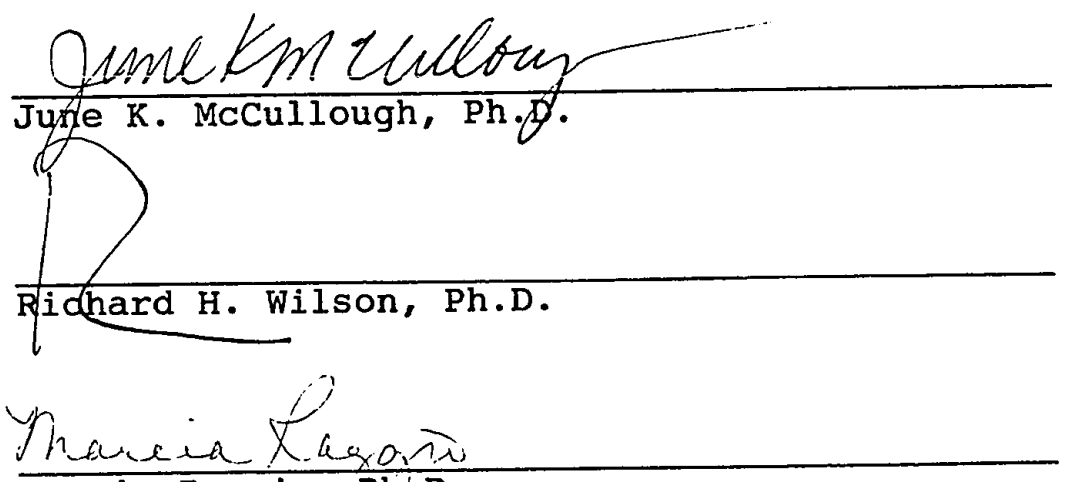

Marcia Raggio, (Ph).D.

APPROVED FOR THE UNIVERSITY

Yn. Lou Sewardovek. 


\section{ABSTRACT}

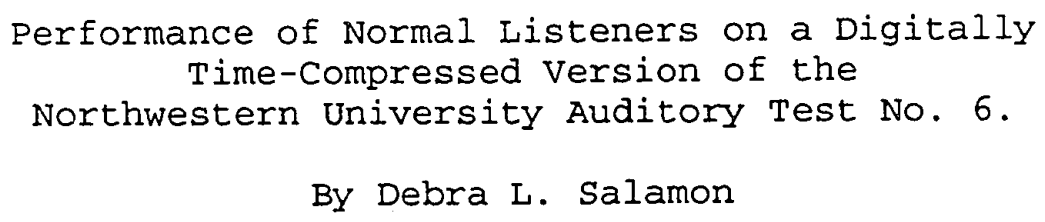

The purpose of this investigation was to obtain normative performance data for a digitally time-compressed version of the Northwestern University Auditory Test No. 6 (female speaker) for listeners with normal-hearing. Subjects were 34 young adults. Two experiments were conducted. In Experiment I, 16 subjects listened monaurally to the NU No. 6 words lists at five compression ratio conditions (45\%, 55\%, 65\%, 70\%, \& 75\%) presented at $70 \mathrm{~dB}$ SPL. In Experiment II, 18 subjects listened monaurally to the stimulus words at three compression ratio conditions (45\%, 65\%, \& 75\%) presented at five levels in $10 \mathrm{~dB}$ increments. The results indicated that word-recognition performance is inversely related to compression ratio and directly related to presentation level. The normative performance data in this study can be utilized in the evaluation of auditory perceptual disorders with normal-hearing adults. 


\section{ACKNOWLEDGMENTS}

I would like to express my gratitude to all the individuals who contributed their time and effort to this project.

First, I would like to express my appreciation to my thesis committee members Richard wilson, Ph. D., Marica Raggio Ph. D., and thesis chair June McCullough, for their scholarly contributions and dedication to helping me.

I would also like to thank John Preece, Ph. D. and Richard Wilson Ph. D. for developing the digital compression technique used in this study.

In addition, I would like to thank Nancy Cambron, Jennifer Sperry and Owen Nishioka, who also contributed their time and assistance to this study. 


\section{DEDICATION}

This thesis is dedicated to my daughter, Jessica salamon, whom I love with all my heart, and to my mother, Mary Eljzabeth Cox, who's love and support made this possible, and finally, to my husband, Sammy E. Salamon, who has always encouraged and supported me throughout my academic career. 


\section{CHAPTER}

INTRODUCTION $\ldots \ldots \ldots \ldots \ldots \ldots \ldots \ldots \ldots \ldots \ldots \ldots \ldots \ldots \ldots \ldots \ldots \ldots$

statement of Problem .................. 4

Purpose of study ..................... 5

Clinical Implications............... 54

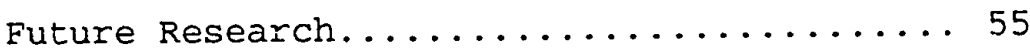

REFERENCES ........................ 57

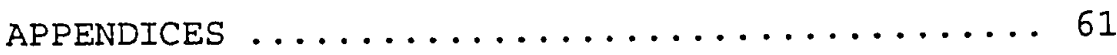


Appendix A. Percentage of Compression by Word

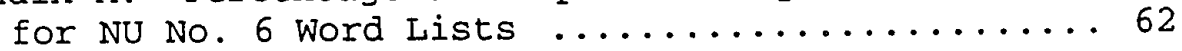

Appendix B. Randomizations of list and Compression Ratio Condition for Experiment II ........... 66

Appendix C. Individual Subject Data For

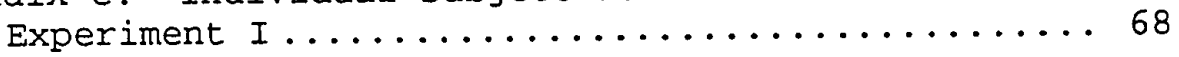

Appendix D. Individual Subject Data for

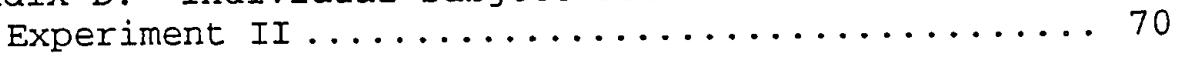

Appendix E. Percent Correct Recognition by Word

for List $I$ and $4 \ldots \ldots \ldots \ldots \ldots \ldots$ 


\section{LIST OF TABLES}

TABLE

PAGE

1. Target compression ratios and corresponding retained and discard intervals ............ 29

2. Mean percent compression and standard deviation of the NU No. 6 lists for the five compression ratio conditions .................... 31

3. Individual subject percent correct recognition of the combined mean of List 1 and 4 for the five compression ratio conditions for Experiment 1 . . 37

4. Mean percent correct recognition for List 1 and List 4 at the five compression ratio conditions for Experiment I.............. 41

5. Mean percent correct recognition for the three compression ratio conditions as a function of increased sound pressure levels for Experiment II ..................... 43 


\section{IIST OF FIGURES}

FIGURE

PAGE

1. Percent correct recognition as a function of presentation level for the compression ratio conditions from Beasley, Schwimmer, and Rintelmann $(1972 a) \ldots \ldots \ldots \ldots \ldots \ldots \ldots \ldots \ldots$

2. Percent correct recogntion as a function of compression ratio for the three studies that have provided normative data for time-compressed

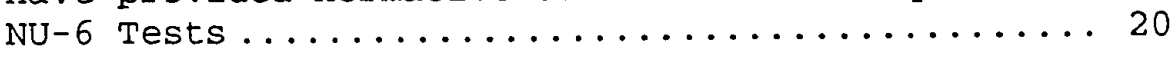

3. Mean percent correct recognition for List 1 and List 4 as a function of the five compression ratio conditions for Experiment I........... 38

4. Mean percent correct recognition for the three compression ratio conditions as a function of increased sound pressure level for Experiment II. 44

5. Mean percent correct recognition grouped in order of presentation for the three compression ratio conditions for Experiment II ........... 49 
CHAPTER I

INTRODUCTION

The term "auditory perceptual disorder" (APD) is used to describe individuals that have difficulty processing the complex network of auditory stimuli which compromise auditory communication. Although controversy in the literature exists regarding the etiologies and characteristics of APDs, it has been established that interference in the central auditory nervous system from the cochlear nuclei to the auditory cortex in the temporal lobe (including the interhemispheric pathways) generally results in APDs (Silman \& Siverman, 1991). The inability to adequately perceive and/or process auditory information is thought to be related to deficits of auditory discrimination, auditory recognition, auditory comprehension, as well as, auditory integration, auditory sequencing, and/or memory. Consequently, individuals with APDs typically demonstrate problems with auditorycommunication behavior, academic/vocational performance, and/or social skills (Matkin, 1983).

Assessment of auditory perceptual function is employed in order to describe the breakdown of auditory processing in patients with various brain lesions (injury to the auditory areas of the brainstem or cortex) and to describe their functional auditory abilities. The results of these tests can be used to determine appropriate remediation and to 
monitor recovery of auditory perceptual functioning (Mueller, Sedge, \& Salazar, 1986).

The goal of the remediation process is to enhance auditory-communication behavior. This is accomplished by concentrating on the development of compensatory strategies that are designed to alleviate the problems associated with auditory deficits (Mueller et al. 1986).

Although a consensus among researchers has not been reached regarding the definitive "auditory perceptual test," researchers are in agreement that a battery of tests sensitive to different anatomical areas of the central auditory system should be utilized in the detection of auditory perceptual disorders (Lass, Riensche, \& Beasley, 1984). One of the tests that has been used effectively in the identification of auditory perceptual disorders involves the use of temporally altered or time-compressed speech materials. In fact, time-compressed speech materials have gained recognition as a simple, sensitive, and valid clinical tool for the detection of auditory perceptual disorders (Grimes, Mueller, \& Williams, 1984). Specifically, time-compressed speech, or temporally altered speech, refers to an acceleration of the speech signal relative to the original speed of the signal. The rational for utilizing temporally altered speech material in the evaluation of auditory perceptual disorders is based on the principle that alterations in the temporal aspects of the 
speech signal reduce the extrinsic redundancies in the speech message and, therefore, tax the central auditory system in a way that noncompressed speech material do not (Silman \& Siverman, 1991).

The technique used to produce the temporal alterations in the speech signal can differently effect the resultant speech signal; therefore, the quality of time-compressed speech recordings is directly related to the technique used to produce the compression (Maki \& Beasley, 1976). Consequently, an important variable in the results of previous research has been the method or technique utilized to produce the temporal alterations in the speech signal. Several methods have been developed to accomplish this task. The earliest techniques were simplistic methods involving moderation of spoken speech or rapid speech production and increased playback time of speech materials. Recently, more advanced techniques have been developed that involve the preservation and deletion of certain segments of the speech signal. This is accomplished by sampling procedures that manipulate the speech signal, either by manual, electromechanical, or computerized methods.

There are advantages and disadvantages to all methods of compression; however, the most efficient and precise technique is the signal processing or computerized method (Maki \& Beasley, 1976). The signal processing method accomplishes the compression process by translating the 
recorded speech materials digitally. A computer program then defines and deletes the portions of the speech sample necessary to produce specific compression ratios. The rejoining of the speech waves is accomplished by inspecting the waveform of each speech sample and splicing the retained portions of the signal together in a manner that produces a smooth transition.

several researchers have provided normative performance information on time-compressed speech materials, spoken by male speakers, for use in the clinical setting (Beasley, Schwimmer, \& Rintelmann, 1972a; Beasley, Forman, \& Rintelmann, 1972b; Riencshe, Konkle, \& Beasley, 1976). These researchers have utilized an electromechanical procedure to produce the compressed speech materials. Normative performance data, however, on word lists that have been compressed using a computerized method are not available. Moreover, normative performance data for time-compressed speech materials, spoken by a female speaker, are also not available.

statement of the Problem

A new digital processing technique recently has been developed to compress the female version of the Northwestern University Auditory Test No. 6. Normative performance data, however, are not available to determine if the technique is a valid measure of time-compressed word-recognition performance. 
Purpose of the study

The purpose of this investigation was to establish normative performance data for a time-compressed version of the Northwestern University Auditory Test No. 6 (female speaker) using normal-hearing adults. The materials were compressed using a digital signal processing technique. 
CHAPTER II

\section{REVIEW OF THE IITERATURE}

Speech materials are routinely utilized in the assessment of word-recognition ability. Speeh materials are not, however, effective in the assessment of central auditory processing disorders (Silman \& Silverman, 1991). It has been established that in order to permit assessment of the central auditory system, the speech stimuli utilized must be "degraded" in some manner. Researchers have accomplished this degradation by altering the temporal aspects of the speech signal and have provided time-compressed versions of conventional speech materials to be used in the assessment of central auditory processing disorders.

The majority of investigators examining the effects of time compression on word-recognition performance have reported that, as the amount of time compression is increased, there must be a simultaneous increase in the intensity of the speech signal in order for optimal wordrecognition performance to occur. Of course, there are upper limits to the amount of compression that can occur before speech is unrecognizable. This can be seen from the equation below:

$$
I=2 \operatorname{tw} \log \frac{\mathrm{S}+\mathrm{N}}{\mathrm{N}}
$$

In which (I) is equal to the amount of information contained in a speech wave; $(t)$ is time in seconds; $(w)$ is width of the 
speech frequency band; $(S)$ is amplitude of the signal and (N) is the value of a just noticeable difference in level (Calearo \& Lazzaroni 1957). The amount of information contained in the speech wave is dependent on each of the factors in the equation. Therefore, reducing the duration (time) of the speech message by compression will decrease the amount of information contained in the speech wave. The amount of compression varies with the technique utilized to degrade the speech signal and also will affect the subsequent speech message. Thus, as stated in the introduction, the method of time compression is a significant variable in the resultant speech signal. There are several methods of time compression that generally fall into two basic categories: acceleration method and speech sampling method. The literature review will focus on the various types of time compression that have been described as well as the normative performance data that have been established for compressed monosyllabic speech materials.

\section{Accelerated Speech Method}

\section{Speaker Acceleration}

One of the earliest ways of producing time-compressed speech was simply to have the "speaker" increase his own rate of discourse. This method was utilized by Goldstein (1949) who examined the effects of accelerated speech on the listening comprehension of 285 subjects (aged 18-65 years). 
Here, time-compressed speech materials were produced by reading aloud text of comprehension tests at different rates of acceleration $(100,137,174,248,285$, and 322 words per minute (wpm)). Goldstein reported that as the rate of compression increased, there was a consistent decrease in listening comprehension. Additionally, the results indicated that the largest decreases in comprehension occurred for the highest compression ratios.

A unique method of speaker acceleration was developed by Diel, White and Burk (1959). These researchers achieved an acceleration in the speech signal by altering only the pause time between words. Diel et al. had a "practiced" speaker produce a recording that was approximately 145 wpm (as judged by three "experts" on speech) after which, silent intervals of $\geq 30 \mathrm{~ms}$ were eliminated. Eliminating the pause times produced a new rate of $174 \mathrm{wpm}$. The recorded material was presented to 81 college-aged students. After listening to the recording, the subjects were instructed to complete questionnaires about the content of the material. Diel et al. concluded that altering the rate of the recorded speech material from 125 to $174 \mathrm{wpm}$ did not interfere with the comprenension of the young adult listeners.

The speaker acceleration method of producing compressed speech materials is limited by the maximum rate of acceleration a speaker can produce without introducing alterations in the spectral characteristics of the speech 
signal (the physiological limit has been noted to be a maximum of $30 \%$ above normal speech (Maki \& Beasley, 1976). Therefore, the accelerated speaker method is unsuitable for producing time-compressed speech materials (Goldstein, 1949).

\section{Accelerated Playback}

Another acceleration technique utilized to produce timecompressed speech materials involved the playback of a recording at a rate faster than the speed of the original recording. The accelerated playback technique was utilized by steinberg (1936), who reported on the effects of timecompressed speech on listening comprehension in 20 university students. The speech stimuli utilized was continuous discourse at increased rates of $14 \%, 28 \%$, and $48 \%$. At each of the accelerated rates steinberg reported that "large losses" in listening comprehension were found.

A similar acceleration method was utilized by Klumpp and Webster (1961) to examine the effect of time compression on the word-recognition ability of five trained listeners. The subjects were presented with speech stimuli (digits, phrases, and phonetically-balanced (PB) word lists) at a "speed-up" time of 1.0 and 1.5 at a signal-to-noise ratio (S/N) of $7 \mathrm{~dB}$. In examining word-recognition scores for the different speech stimuli, Klumpp and webster found that digits produced the highest scores, with phrases the second highest, followed by the PB word lists. These researchers also reported that at 
the highest rate of compression, the subjects PB scores decreased from $62 \%$ to $45 \%$. Klumpp and webster concluded that even at a "speed-up" time of 50\% (1.5 Playback), intelligibility remained at a 908 despite the resultant frequency shifts. These reductions in listening comprehension, however, may be related to frequency distortion and not due to the affects of the accelerated speech materials (Garvey, 1953).

Acceleration methods were utilized in the earliest studies of time-compressed speech materials. Because of their obvious limitations (the most prominent being the resultant frequency shifts), acceleration methods have been made obsolete by more advanced methods of compression that involve the sampling of the speech signal.

\section{Sampling Techniques}

Sampling techniques have several advantages over the accelerated time compression methods. First the techniques provide a more precise method of producing compressed materials while eliminating the frequency distortion produced by the earlier acceleration method. In addition, higher compression ratios are possible with the sampling techniques.

In general, sampling techniques accomplish the compression of the speech signal by deleting certain segments of the speech wave. Elimination of segments is referred to as the "discarded interval." Alternatively, the segments 
that are retained are labeled the "sampled interval." The sampled intervals are abutted in time and rejoined to complete the compression process. Researchers have accomplished sampling through manual, electromechanical, and computerized methods. These studies will be the topic of the following review.

\section{Manual Sampling Technigue}

The manual method was used in the early part of the 1950 s to produce time-compressed speech materials. The manual method has also been called "chop and splice" method because the technique involved the tedious process of manually chopping and then splicing portions of an audio tape back together (Garvey, 1953). The major advantage of the manual method was that the linguistic content of the speech signal could be modified more precisely than other methods available at that time (Lee, 1972). The manual procedure, however, is extremely time consuming, and requires spectrographic verification of the success of the segmentation (Garvey, 1953).

The manual method first was introduced by Garvey (1953) in an attempt to produce time-compressed speech without the resultant frequency shift associated with the acceleration methods. The procedure developed by Garvey involved taking the tape of speech material to be compressed and recording it onto a "plastic base tape." Then, the beginnings and endings 
of each word were marked along with the portions of the tape to be eliminated. Once all this was accomplished, the remaining segments of tape were spliced back together. Garvey noted that tape of compressed speech had to be played back at the original recording speed in order for the "voice quality" of the original tape to be maintained.

Garvey investigated the effects of time-compressed speech upon word intelligibility by presenting spondiac word lists to 69 college students at various "speed up rates." The rates ranged from 1.5 to 4.0 , which are equal to $33 \%$ and 75\% compression ratios. All the stimuli were presented at $42 \mathrm{~dB}$ above the pure tone threshold.

The results indicated that for the rates of $1.5,1.75$, and 2.0, intelligibility scores remained high (above 95\%). In addition, the rate of 2.5 produced scores that were still above $90 \%$. Finally, the results showed that the accelerated rates of $3.0,3.5$, and 4.0 produced scores of $78 \%, 50 \%$, and $40 \%$ respectively. Garvey concluded that speech intelligibility remained unaffected until high compression ratio conditions were utilized.

Additionally, Garvey examined speech intelligibility relative to the size of the discard interval ("size of the chop"). The results indicated that large portions of the speech signal could be removed without appreciable losses in intelligibility of the speech signal. Specifically, Garvey reported that it was not until the size of the "removed chop" 
was three times as large as the unremoved section (which corresponds to the $75 \%$ compression ratio) that the mean intelligibly score dropped below the $50 \%$ level.

As discussed earlier, the manual method of producing time-compressed speech materials is a very time consuming procedure and therefore, other researchers looked for less exhausting methods to achieve the same quality of timecompressed materials. This search lead to the development of an electromechanical process of producing temporal altered speech materials.

\section{Electromechanical Sampling Technique}

In 1954, Fairbanks, Everitt, and Jaeger designed an electromechancial device that was a much more efficient method of producing time-compressed speech materials, while maintaining the original spectrum of the speech sample. The apparatus consisted of a tape loop system that was composed of four rotating heads. The tape to be compressed was put through this loop system. One of the four heads would periodically come in contact with the tape and thereby, "sample" the segment to be retained with its original power spectrum. The retained interval then would be transferred to a variable speed storage tape recorder. The portions of the tape that were not sampled were defined as the discard intervals and were manipulated by changing the relative positioning of the rotating heads. Specifically, the discard 
interval was defined as the amount of separation between the two heads divided by the tape speed. The amount of compression was controlled by varying the relative velocity between the tape loop and the rotating head assembly.

Although the electromechanical sampling technique was the most efficient method of producing compressed materials, there were still several drawbacks with the apparatus. For example, Lee (1972) reported that close monitoring of the electromechanical device needed to be employed in order to avoid amplitude modulation of the signal, since the apparatus contained high speed rotating mechanical components. In addition, other researchers have commented that the discarded and sampled intervals cannot be controlled relative to linguistic content of the materials to be compressed (Maki \& Beasley, 1976).

Lee (1972) developed the Varispeech 1, a device that was based on the Fairbanks compressor, with the added advantage of having a minicomputer replace its mechanical components. This device was small and inexpensive; however, as with the Fairbanks compressor, the varispeech 1 did not have the capability of linguistic segmental manipulation.

The majority of normative data currently available for time-compressed speech materials were produced by the electromechanical type of apparatus. The review that follows will emphasize studies that have utilized monosyllabic timecompressed speech materials, spoken by male talkers, to 
investigate word-recognition performance of normal-hearing subjects.

Beasley, Schwimmer, and Rintelmann (1972a) examined the effects of varying compression ratio and presentation level on word-recognition ability of 96 normal-hearing young adults. The subjects were assigned to six experimental groups, corresponding to six different compression ratios 10\%, 30\%, 40\%, 50\%, 60\%, and 70\%). Each subject was presented with the four lists of Form $B$ of the Northwestern University Auditory Test No.6 (NU-6). The lists were presented at one of the following levels: $8,16,24$, and $32 \mathrm{~dB}$ above the speech-recognition threshold (SRT).

In order to alter the temporal characteristics of the speech material to the appropriate time compression ratios, a copy was made of the Rintelmann and Jetty (1968) version of the NU-6 word lists and temporally altered utilizing the Fairbanks electromechancial time-compressor. In addition, the researchers interjected 5 seconds intervals between each word to allow for response time.

Beasley et al. (1972a) reported that as the compression ratio gradually increased from 30-60z, the intelligibility of the word lists decreased; with the exception of the $70 \%$ compression ratio condition where they found a sharp reduction in intelligibility. In examining the relationship between presentation level and compression ratio upon intelligibility, Bealsey et al. reported that for every 
increase in presentation level there was a corresponding increase in intelligibility of the test stimuli with the effects decreasing as the optimal listening condition was approached. The effect, however, was pronounced at the $70 \%$ compression ratio at which each increase in presentation level produced a significant improvement in the wordrecognition performance (see Figure 1). Beasley et al. concluded from the results that at the higher compression ratios normal-hearing listeners may not have enough time or information to process perceptually incoming verbal stimuli; therefore, they recommended that compressed monosyllabic materials should not be employed above a compression ratio of 60\%. Unfortunately, these researchers did not verify the amounts of compression that they actually achieved. Consequently, this recommendation can not be generalized to other compressed speech materials that have been compressed via other techniques.

Beasley, Forman and Rintelmann (1972b) expanded on the earlier research of Beasely et al. (1972a). These researchers utilized the same parameters as the previous study, except Beasley et al. (1972b) utilized only one presentation level ( $40 \mathrm{~dB}$ above SRT). (The previous researchers used a maximum presentation level of $32 \mathrm{~dB}$ above SRT). The subjects were 16 normal-hearing listeners who were between the ages of $18-26$ years. The results revealed an inverse relationship between intelligibility and compression 


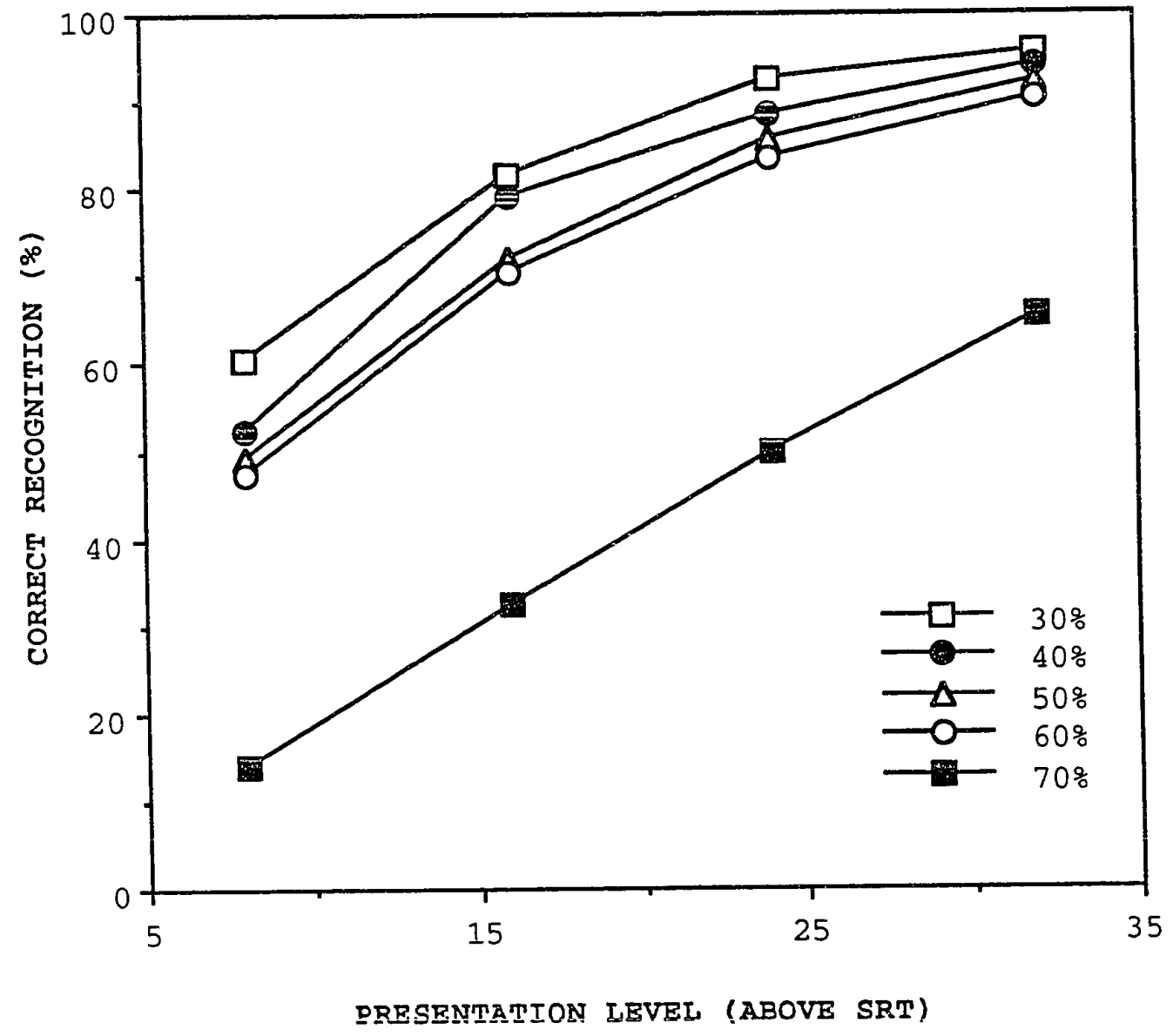

FIGURE 1. Percent correct recognition as a function of presentation level for the five compression ratio conditions from the data of Beasley, Schwimmer, and Rintelmann (1972a). 
ratio. Comparison of results with the data of Beasiey et al. (1972a) indicated that maximum word-recognition performance were obtained at a presentation level of $32 \mathrm{~dB}$ (above SRT) for all conditions, except for the $70 \%$ compression ratio condition for which maximum word-recognition performance may not have been reached even at a presentation level of $40 \mathrm{~dB}$ (above SRT).

In an attempt to determine the reliability of earlier findings and to provide additional word-recognition material, Riensche, Konkle, and Beasley (1976) obtained normative data on time-compressed versions of Form $A$ of the NU-6 word lists. The compressed word lists were presented to 80 normal-hearing young adults (aged 18-26). The stimuli (NU-6 word lists recorded by Rintelmann \& Associates 1974) were compressed utilizing a varispeech 1 speech compressor. The subjects were presented with one of the six compression ratios $10 \%$, $30 \%, 40 \%, 50 \%, 60 \%$ ) with each list presented at a different presentation level $(8,16,24,32 \mathrm{~dB}$ above SRT). Riensche et al. reported findings similar to previous studies; performance decreased as a function of increasing compression ratio and decreasing presentation level.

To investigate whether equivalent word-recognition tasks maintain the same level of difficulty when temporally altered, De chicchis, Orchik, and Tecca (1981) examined wordrecognition performance for the time-compressed versions of the NU-6 and the CID $\mathrm{W}-22$ word lists. The Auditec recording 
of each list was presented to 28 subjects aged $18-28$ years at five compression ratios $10 \%, 30 \%, 40 \%, 50 \%$, and $60 \%$ ) at a presentation level $40 \mathrm{~dB}$ (above SRT). The compression of the stimuli for both recordings was carried out utilizing the Varispeech II time-compressor. De Chicchis et al. reported that, indeed, the NU-6 and CID $\mathrm{W}-22$ tests did yield significantly different results for the $30 \%$ and $60 \%$ compression ratios, despite the fact that these two wordrecognition tasks were reported to be equivalent in an unaltered form for normal-hearing listeners (Beattie, Edgerton, \& Svihovec, 1977). De Chicchis et al. concluded that equivalent, unaltered speech materials may not be equivalent when time-compressed.

In order to investigate the hypothesis that significantly different word-recognition performance results from recordings that employ different speakers, De Chicchis et al. (1981) compared performance data for the Auditec of St. Louis recorded version of the NU-6 word lists to the NU-6 performance data from Beasley et al. (1972a) who used the Rintelmann (1974) recording of the NU-6 word lists. The results are depicted in Figure 2. (For reference, the data from additional studies that have provided normative information for NU-6 time-compressed speech materials using the Rintelmann recording are also depicted (Beasley et al. (1972b); Riensche et al. (1976)). The results indicated that the time-compressed NU-6 speech materials produced by 


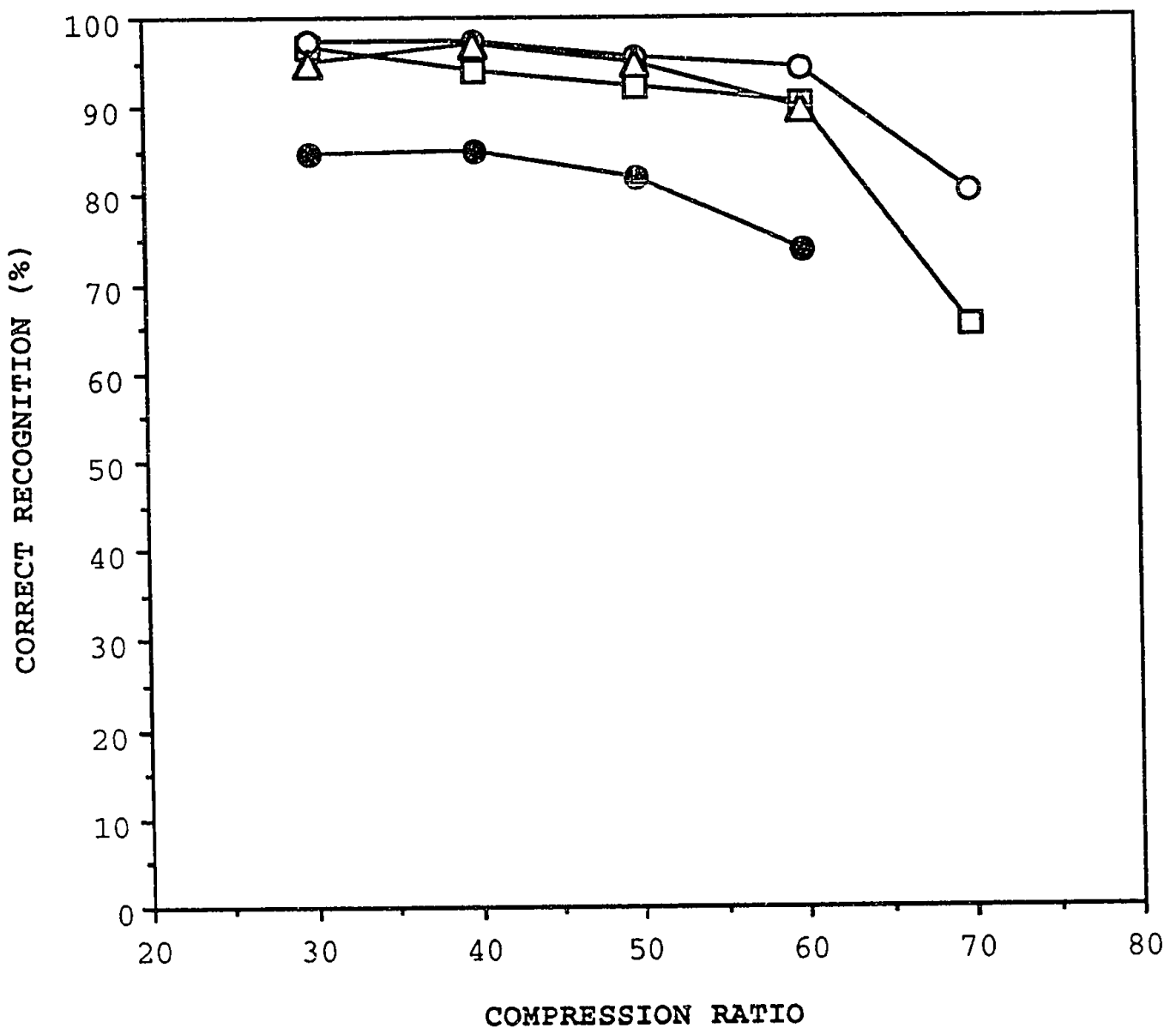

FIGURE 2. PSychometric functions from the data of Beasley, Schwimmer and Rintelmann (1972a) (squares), Beasley, Forman, and Rintelmann (1972b) (circles), and Riensche, Konkle and Beasley (1976) (triangles). For reference the De Chicchis, Orchik and Tecca (filled circles) data is also shown. 
different speakers yielded significantly different psychometric functions. Specifically, for the $60 \%$ compression ratio, the mean scores were approximately 16\% poorer for the Auditec version of the NU-6 word lists than for the NU-6 word list recorded by Rintelmann (1974). Similar discrepancies were reported by Grimes, Mueller, and Williams (1984) who examined the effects of timecompression on the equivalency of NU-6 word lists. These researchers presented the time-compressed NU-6 Auditec recordings to 28 normal-hearing subjects (aged 19-37) and 28 hearing-impaired subjects (aged 25-59). The Auditec recordings were the commercially available compressed versions of Form A NU-6 lists. The lists were originally compressed utilizing the Varispeech II compressor. The subjects listened to the word lists at a compression ratio of $60 \%$ presented at a level of $32 \mathrm{~dB}$ above the speech recognition threshold. The list order was counterbalanced and in addition, the subjects were assigned a specific order of lists. In determining interlist equivalency, Grimes et al. reported a significant difference between the mean scores derived from List III compared to Lists I, II, and IV. Specifically, the results demonstrated that for the normalhearing group, the mean scores ranged from a high of $75 \%$ for List I to $66 \%$ for List III. The results for the hearingimpaired group, revealed that the mean scores fell approximately $35 \%$ to $40 \%$ below the scores of the normal- 
hearing group. Grimes et al. concluded that although NU-6 lists are equivalent in their original form, the lists do not respond equally to the effects of time compression.

In evaluating learning effects due to order of list presentation, Grimes et al. (1984) reported that the mean scores for the first and second presentations were significantly different between List III and IV for the normal-hearing listeners. Grimes et al. concluded, however, that because no differences were found between the first and second presentations, these lists could still be utilized in the clinical setting without any contaminant effects due to learning. These researchers did, however, recommend that the audiologist should avoid utilizing List III, in particular, due to the significantly poorer scores obtained by both subject groups.

Both the Grimes et al. (1984) and the De Chicchis et al. (1981) studies indicate that word lists that are equivalent in a nonaltered form may not be of equal difficulty after having been temporally altered. These data underscore the importance ố obtaining normative information for timecompressed materials even though the same word lists have already been standardized in their noncompressed forms. Moreover, the results of De Chicchis et al. indicate that normative data should be obtained for each individual speaker of time-compressed speech materials. 
In summary, the electromechanical techniques of producing time-compressed materials have been utilized for obtaining the normative data currently available for monosyllabic compressed word-recognition tests. Although the advent of electromechanical devices did eliminate some of the disadvantages of the earlier procedures for producing timecompressed materials, the devices still had the potential disadvantage of producing amplitude modulation. The introduction of computerized compression techniques was designed to eliminate the problem of potential alterations in the amplitude of the speech signal.

\section{Computerized Technicues}

Computerized techniques of producing time-compressed speech materials involve utilizing analog-to-digital converters that translate the speech information into binary digits. Once the information is stored, a computer program is utilized to specify the appropriate discard interval needed to obtain specific amounts of time compression. The manipulation of the waveform (deletion of the discard interval and rejoining of the sampled intervals) is made more efficient by the ability to visualize the waveform on the computer monitor. After the speech information has been compressed, a digital-to-analog converter translates the binary digits into an analog speech signal. 
The utilization of the computer to produce compressed speech materials allows for alterations in the speech signal at the linguistic level; therefore, the relative importance of phonemes can be studied in relationship to the intelligibility of the speech signal. In addition, the computer-aided technique permits smooth transitions to be obtained once the discard intervals are eliminated and the sampled intervals are rejoined. Compression ratios can also be programed easily and the amount of compression actually obtained can be calculated with precision.

To date, computerized techniques for producing timecompressed speech materials have not yet been utilized to produce materials for use in the clinical testing situation. Summary

In summary, there are several methods of producing timecompressed speech materials. The earliest research was conducted utilizing acceleration techniques that were limited by the maximum amount of compression that could be produced. Additionally, acceleration techniques had the disadvantage of producing shifts in the frequency of the original recordings. The frequency distortions were eliminated with the advent of sampling techniques. As pointed out in the literature review, the manual methods were extremely time consuming. In addition, the electromechanical technique required that the speech signal be monitored for possible amplitude alterations. 
Computerized techniques for producing time-compressed speech materials allow for alterations at the linguistic level, provide smooth transitions, and facilitate accurate computation of compression ratio. Time-compressed speech materials, however, are not available that have been compressed by computer techniques. Moreover, the normative data currently available for time-compressed NU-6 word lists have employed male speakers. The goal of this study was to develop a compressed version of the NU No. 6 materials (female version) utilizing a computerized technique and to standardized the materials with normal-hearing young adults. 
CHAPTER III

METHODOLOGY

Time-compressed word-recognition materials are utilized in the assessment of auditory perceptual disorders. Typically, an audiologist presents the compressed wordrecognition tests via a recording. A recording of timecompressed NU No. 6, spoken by a male speaker, is available for which normative performance information has been described (Beasley et al., 1972a, Beasley et al., 1972b, \& Riencshe et al., 1976). Moreover, it has been established that different psychometric functions are obtained when different speakers of recorded speech materials are used (Kruel, Bell, \& Nixon, 1969). In addition, several investigators have reported that norms established for nonaltered speech materials can not be utilized for the same speech materials in the compressed form (Grimes et al.. 1981; De chicchis et al., 1976). Therefore the purpose of this study was to establish normative data for the NU No. 6 test for the female version (Wilson, Zizz, Shanks, \& Causey 1990) utilizing a digital processing technique in the generation of the compressed materials. Once the normative performance data have been established for this technique, the timecompressed $\mathrm{NU}-6$ word list can be made available commercially on compact disc. 
Research Design

Two experiments were conducted. In Experiment $I$, percent correct performance for NU No. 6 Lists 1 and 4 at five compression ratio conditions $145 \%, 55 \%, 65 \%, 70 \%$, and $75 \%$ ) were obtained in quiet at $70 \mathrm{~dB}$ sound-pressure level (SPL). Two randomizations of each word list were made for each of the five compression ratio conditions. Each subject listened to a randomization of List 1 and List 4 under each compression ratio condition. The presentation order of the ten lists for each subject was randomized. In Experiment II, psychometric functions in quiet for the four lists of NU No. 6 were generated for 18 subjects for three compression ratio conditions $(45 \%, 65 \%$, and $75 \%)$. The following levels were used with the respective compression ratios: at $45 \%$ compression $30,40,50,60$, and $70 \mathrm{~dB} \mathrm{SPL}$; at $65 \%$ compression $35,45,55,65$, and $75 \mathrm{~dB}$ SPL; at $75 \%$ compression, 50, 60, 70, 80 and $90 \mathrm{~dB}$ SPL. To minimize learning effects, all testing was sequential from the lowest level the highest level. For each subject and each condition, the order of the four lists was randomized for the first four levels with the list used at the lowest level repeated at the highest level (The specific order of list presentation can be found in Appendix B.).

The Instrument

The female recording (Wilson et al., 1990) of the NU No. 6 Test (Tillman \& Carhart, 1966), consisting of four 
lists of 50 monosyllabic phonetically-balanced words, served as the base structure for the time-compressed recording. The analog recording (Revox, Model B77) of the original tape was processed via a analog to digital converter (Antex, Model sX-10) utilizing at 20,000 samples/sec with an anti-alaising filter setting of $8,800 \mathrm{~Hz}$ (96 dB/octave rejection). The compression technique utilized was developed for this research project and has been previously described in detail by Wilson, Preece, Salamon, Sperry, \& Bornstein (1993). The following is a summary of that process. Following the digitization of each speech sample (target word and carrier phrase) a BASIC program was utilized to identify the target discard intervals. A target discard interval of 20 to $25 \mathrm{~ms}$ was selected. Table 1 displays the initial retained and discard intervals established by the program for the respective compression ratios. All data points in the discard interval were set to zero, then all data points in the discard interval were deleted, except eight points that were retained to mark the segement boundary. By inspecting the waveform of each speech sample the eight data points were identified and were eliminated in a procedure that resulted in a smooth transition between the remaining waveforms. The procedure consisted of the following rules:

In order to join the waveforms: 1) with noise on both sides of the discard interval as with the /s/, $/ f /, / z /$ sounds, the waveforms were joined simply by eliminating the zeroed data points and several adjacent data points; this resulted in a nominal 
Table 1

Target compression Ratios (in percent) with the corresponding Retained and Discard Intervals (in milliseconds).

\begin{tabular}{|c|c|c|}
\hline Compression Ratio & Retained Interval & Discard Interval \\
\hline \hline $40 \%$ & $27.0 \mathrm{~ms}$ & $18 \mathrm{~ms}$ \\
$50 \%$ & $18.0 \mathrm{~ms}$ & $18 \mathrm{~ms}$ \\
$60 \%$ & $12.0 \mathrm{~ms}$ & $18 \mathrm{~ms}$ \\
$65 \%$ & $9.7 \mathrm{~ms}$ & $18 \mathrm{~ms}$ \\
$70 \%$ & $7.7 \mathrm{~ms}$ & $18 \mathrm{~ms}$ \\
\hline
\end{tabular}


20-ms discard interval; 2) with periodic waveforms on both sides of the discard interval, up to one cycle and the zeroed data points were eliminated with the waveforms joined at a common point on the cycle, usually at the positive going or the negative going zero crossing; this produced a $20-\mathrm{ms}$ to 25-ms discard interval; 3) with aperiodic waveform adjacent to a noise waveform (or visa versa), the zeroed data points were eliminated and the waveforms were joined at crossing; this produced a 19-ms to 21-ms discard interval. (p.7)

The original compression ratios targeted $(40 \%, 50 \%, 60 \%, 65 \%$, and $70 \%$ ) were based on a discard interval of $18 \mathrm{~ms}$. The majority of the speech samples, however, required more than the elimination of the targeted $18 \mathrm{~ms}$. The corresponding data files for each compression ratio were calculated and the results indicated that the compression ratios actually produced were approximately five percent larger than originally targeted. Consequently, the compression ratios actually utilized were 45\%, 55\%, 65\%, 70\%, and 75\%. Table 2 shows the mean duration of the noncompressed speech files along with the mean percent of compression for each of the NU No. 6 word lists under each of the five compression ratios conditions. A list of the compression ratios for the individual words in Lists $1-4$ is found in Appendix A. The compressed materials were output from the computer via a 16-bit digital-to-analog converter (Antex, Model Sx-10) and recorded on digital audio tape or DAT (Sony, Model PCM2500A). 
Table 2

Mean Duration (ms) and the standard Deviation of the Noncompressed speech Files. Also shown are the mean Percent Compression and Standard Deviations for Each of the NU No. 6 Lists Under Each Compression Ratio Condition.

\begin{tabular}{|c|c|c|c|c|c|c|}
\hline & \multirow{2}{*}{$\begin{array}{c}\text { 08 } \\
\text { Compression } \\
\text { ms }\end{array}$} & \multicolumn{5}{|c|}{ Compression } \\
\hline & & $45 \%$ & $55 \%$ & $45 z$ & $70 \frac{8}{8}$ & 75 \\
\hline List 1 & & & & & & \\
\hline Mean & 1291 & 435 & 54.3 & 65.5 & 70.3 & 75.5 \\
\hline STD DEV & 74 & 0.9 & 0.9 & 1.1 & 0.9 & 1.1 \\
\hline List 2 & & & & & & \\
\hline Mean & 1226 & 44.7 & & 66.6 & & 76.7 \\
\hline STD DEV & 78 & 1.1 & & 0.9 & & 1.5 \\
\hline List 3 & & & & & & \\
\hline Mean & 1238 & 43.7 & & 64.7 & & 75.7 \\
\hline STD DEV & 88 & 0.9 & & 0.9 & & 1.5 \\
\hline List 4 & & & & & & \\
\hline Mean & 1309 & 43.7 & 54.1 & 65.6 & & 75.8 \\
\hline STD DEV & 70 & 1.1 & 0.8 & 1.1 & & 1.1 \\
\hline
\end{tabular}




\section{Subjects}

Subjects for the first experiment were 16 young adults between the ages of 17-28 years old with a mean age of 24 years. The majority of subjects were health care professionals and college students. The second experiment included 18 young adult listeners between the ages of 17-28 with a mean age of 25 years old. The majority of the subjects were college students with the addition of three professional health care workers. The college students were recruited from Long Beach State University.

\section{Procedures}

All subjects received an audiological evaluation utilizing the following protocol: 1) case history; 2) otoscopy; 3) pure tone audiometrics; thresholds $\leq 15 \mathrm{~dB} \mathrm{HL}$ (ANSI, 1989) at octave intervals from 250-8000 and with the addition of $3000 \mathrm{~Hz}$ and $6000 \mathrm{~Hz}$, in the test ear. All testing was conducted in a sound treated room (IAC, Model 1204A). The stimuli were recorded on DAT (Sony, Model PCM2500A) and fed through an audiometer (Grason-stadler, Model 10). For all test conditions subjects listened monaurally to compressed NU No. 6 word lists in quiet through TDH-50P earphones encased in a $\mathrm{P} / \mathrm{N}$ 510C017-1 cushion.

For Experiment I, two randomizations of Lists 1 and 4 were generated and the order of presentation was randomized. The stimuli were presented at $70 \mathrm{~dB}$ SPL at five compression ratios $(45 \%, 55 \%, 65 \%, 70 \%$, and $75 \%)$. To reduce the 
potential for learning effects, the presentation order of the ten lists for each subject was randomized.

In Experiment II, nine randomizations of word Lists 1, 2,3 , and 4 were used. The three compression ratio conditions $(45 \%, 65 \%$, and 75\%) were counterbalanced and subjects were assigned to one of six experimental conditions (See Appendix B). For each compression ratio, the presentation level was increased in $10 \mathrm{~dB}$ increments from lowest to highest to reduce the potential for learning effects. In order to achieve maximal word-recognition performance, the presentation levels were increased with increasing compression ratio. Specifically, the levels utilized were; at the $45 \%$ compression ratio: $30,40,50,60$, and $70 \mathrm{~dB}$ SPL; at the $65 \%$ compression ratio: $35,45,55,65$, and $75 \mathrm{~dB}$ SPL; and finally, at the $75 \%$ compression ratio: 50 , $60,70,80$, and $90 \mathrm{~dB}$ SPL. To reduce possible order effects, the order of the four lists was randomized for the first four levels with the list presented at the lowest level repeated at the highest level.

All subjects were given standard instructions: "You will hear the phrase 'Say the word'. At the end of the phrase there will be a one syllable word that you must write on the appropriate space provided on your response sheet." Subjects were additionally instructed to "mark each space on the response sheet even if you can not guess at the target word" and to "write as legibly as possible, however, spelling 
errors do not matter." In addition, the examiner periodically checked the response sheet of the subjects to ensure that the instructions were being followed and that the responses were written in the appropriate spaces.

\section{Data Analysis}

The purpose of the data analysis was to provide normative data for a time-compressed version of the NU Auditory Test No. 6 spoken by a female. Percent correct recognition for the NU No. 6 target words was obtained for each subject in each of the five experimental conditions for Experiment I and the six experimental conditions in Experiment II. The percent correct recognition scores then were calculated and averaged to establish mean percent correct. The t-test for independent means was utilized to analyze the difference between mean percent correct data. For all comparisons a confidence interval of $t=0.05$ was used. Standard deviations were also calculated for each experimental condition. In addition, psychometric functions were established for the data from Experiment II. 
CHAPTER IV

\section{RESULTS AND DISCUSSION}

The purpose of this investigation was to establish normative performance data for a digitally time-compressed version of the NU No. 6 (female speaker) word-recognition test. Two experiments were conducted. The first experiment was designed to examine the relationship between wordrecognition performance and the percent of time compression. In the second experiment, the relationship between timecompressed word-recognition was examined relative to presentation level. Analysis of the results included establishing mean and standard deviation data for the timecompressed NU NO. 6 materials for each of the expeximental conditions. Statistical anlaysis included deteriming if significant differences existed among the mean data for the two experiments. For all comparisons a confidence interval of $t=0.05$ was utilized. Interlist equivalency (for Lists 1 and 4) also was examined. In addition, the results of the the second experiment were analyzed for potential contamination due to learning effects. Finally, an error analysis of the target words utilized in Experiment I was conducted.

Experiment I

In Experiment I, 16 subjects listened monaurally to two randomizations of Lists 1 and 4 at five compression ratio 
conditions $(45 \%, 55 \%, 60 \%, 65 \% \& 75 \%)$ presented at $70 \mathrm{~dB}$ SPL. Presented in Table 3 are the individual percent correct recognition scores for the mean of Lists 1 and 4 as a function of the five compression ratios (The individual percent correct recognition scores for List 1 and 4 separately are shown in Figure 3 and presented in Appendix C). Also shown in this table are the mean and standard deviations obtained at each compression ratio. The means for the corresponding five compression ratio conditions $(45 \%, 55 \%, 60 \%, 65 \%, 75 \%)$ were as follows: $90.3 \%, 84.5 \%$, 70.3\%, 51.1\%, and 24.6\%. The respective standard deviations were $3.4,4.3,8.7,12.1$, and 11.1. Mean percent correct recognition performance ranged from $90 \%$ at the smallest compression ratio utilized (45\%) to $25 \%$ at the highest level of compression (75\%). The pattern in the table indicates that a moderate and consistent decline in correct recognition performance occurred between $45 \%$ to $65 \%$ compression ratio conditions. At higher compression ratios (65-75\%) there was an even greater deterioration in word-recognition performance. Specifically, correct percent word-recognition performance declined $25 \%$ at the smaller compression intervals (45-55\&55-65\%) and doubled to approximately 50\% decline at the highest compression intervals (65-70\&70-75\%). Depicted in Figure 3 are the psychometric functions for List 1 (represented by circles) and List 4 (represented by squares). The mean percent correct word-recognition 
Table 3

The individual subject correct recognition scores (in percent correct) for the mean of NU No, 6 List 1 and 4 for the five compression ratios presented at $70 \mathrm{~dB}$ SPL for Experiment I.

\begin{tabular}{|c|c|c|c|c|c|}
\hline \multirow{2}{*}{ Subject } & \multicolumn{5}{|c|}{ Nominal Compression } \\
\cline { 2 - 6 } & 45 & 55 & 65 & 70 & 75 \\
\hline 1. & 90 & 83 & 61 & 48 & 23 \\
2. & 95 & 91 & 82 & 66 & 42 \\
3. & 91 & 87 & 64 & 48 & 21 \\
4. & 93 & 89 & 82 & 73 & 50 \\
5. & 87 & 84 & 58 & 35 & 22 \\
6. & 93 & 81 & 79 & 59 & 22 \\
7. & 88 & 86 & 58 & 48 & 11 \\
8. & 87 & 80 & 63 & 38 & 13 \\
9. & 86 & 81 & 71 & 54 & 18 \\
10. & 92 & 85 & 67 & 55 & 13 \\
11. & 95 & 89 & 78 & 66 & 31 \\
12. & 96 & 95 & 79 & 55 & 22 \\
13. & 89 & 80 & 62 & 36 & 16 \\
14. & 90 & 81 & 70 & 32 & 20 \\
15. & 87 & 83 & 71 & 45 & 31 \\
16. & 86 & 84 & 79 & 59 & 38 \\
& & & & & \\
MEAN & 90.3 & 84.9 & 70.3 & 51.1 & 24 \\
ST DEV & 3.4 & 4.3 & 8.7 & 12.1 & 11 \\
MIN & 86 & 80 & 58 & 32 & 11 \\
MAX & 96 & 95 & 82 & 73 & 50 \\
RANGE & 10 & 15 & 24 & 41 & 39 \\
\hline
\end{tabular}




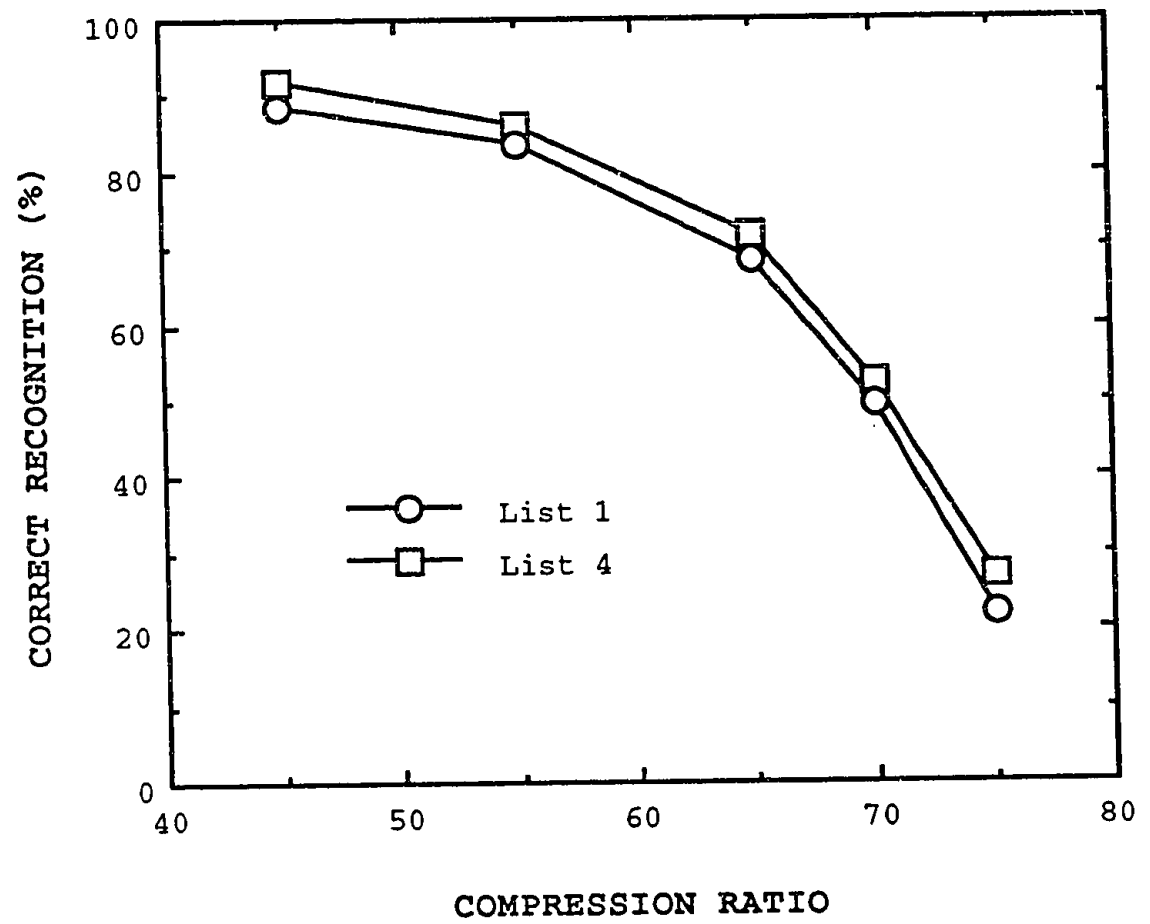

FIGURE 3. Mean percent correct recognition for List 1 (circles) and List 4 (squares) as a function of the five compression ratio conditions from Experiment I presented at $70 \mathrm{~dB}$ SPL. 
performance is plotted as a function of compression ratio. The slope of the function was characterized by a slight decline at the smaller compression ratios $(45-65 \%)$ and a steeper decline at higher compression ratios $(65-75 \%)$. These data clearly show that compression ratio is inversely related to word-recognition performance. The general pattern of declining word-recognition performance with increasing levels of time compression and a greater deterioration in performance at higher compression ratios is consistent with previous studies (Beasley et al. 1972a; Beasley et al. 1972b; Riensche et al. 1976). A direct comparison, however, between these later studies and the present investigation cannot be made in view of the fact that earlier studies that provided normative data for a time-compressed NU No. 6 materials varied the parameters of compression ratio and presentation levels, utilized a different recording/compression technique (mechanical apparatus: i.e., Fairbanks electromechanical time-compressor vs the Varispeech I speech compressor), and most importantly, used a male recording of the NU-6 wordrecognition test. Moreover, the amount of compression actually produced was not verified by the previous investigations. Therefore, in comparing the results of the present study to previous investigations the overall "general pattern" of the results will be discussed rather than attempting to make a direct comparison. 
List equivalency for List 1 and 4 also was examined. The mean percent correct for List 1 was $88.8 \%, 83.8 \% 68.6 \%$, $49.6 \%$, and $22.3 \%$ for the compression ratios of $45 \%, 55 \%, 65 \%$, $70 \%$ and $75 \%$ respectively. For the corresponding compression ratios the mean percent correct for List 4 was $91.9 \%, 86.1 \%$, $71.9 \%, 52.5 \%$, and $26.9 \%$ respectively. Table 4 presents the mean and standard deviation data for List 1 and 4 separately. Statistical analysis of the data revealed that Lists 1 and 4 were equivalent at the 55\%, 65\%, 70\%, and $75 \%$ compression ratios conditions $(E(30)=1.30 ; R . \leq .05 ; t(30)=0.96$,

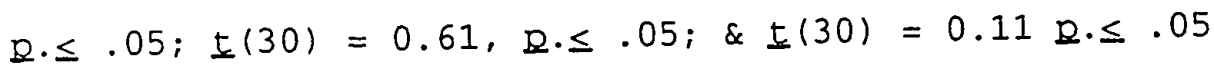
respectively) but significantly different at the $45 \%$ compression ratio condition $(t(30)=2.13, \underline{2}(\leq .05)$ with Iist 4 resulting in slightly better word-recognition scores. These data support the conclusion of previous investigations that temporally altered speech material may not maintain original word list equivalency (Beasley et al., 1972a; Beasley et al., 1972b; Grimes et al., 1984). For example, Beasley et al., (1972b) found that Lists 1 and 4 were equivalent at the $35 \%$ and $50 \%$ compression ratios yet differed significantly at other compression levels (40\%, 60\%, \& 70\%). In addition, Grimes et al. (1984) reported that interlist equivalency was maintained for all the NU No. 6 word lists at the compression ratio of $60 \%$ except for List III. Most importantly, the Grimes et al. data indicated that at the level of compression utilized for clinical purposes $160 \%$ \& 
Table 4. Mean Percent Correct Data and Standard Deviations for List 1 and 4 at the Five compression Ratio conditions Presented at $70 \mathrm{~dB}$ SPL in Experiment I.

\begin{tabular}{|c|c|c|c|c|c|}
\hline \multirow{2}{*}{} & \multicolumn{5}{|c|}{ Compression Ratio (8) } \\
\cline { 2 - 5 } & 45 & 55 & 65 & 70 & 75 \\
\hline \hline List 1 & & & & & \\
STD & 48.7 & 83.7 & 68.6 & 49.6 & 22.3 \\
List 4 & 4.6 & 5.6 & 10.3 & 14.9 & 13.4 \\
Mean & 91.9 & 86.1 & 71.9 & 52.5 & 26.9 \\
STD & 4.7 & 4.7 & 8.8 & 11.5 & 10.7 \\
\hline
\end{tabular}


$65 \%$ compression ratio) Lists 1 and 4 were found to be equivalent.

\section{Experiment II}

In Experiment II, 18 subjects were assigned to one of six experimental conditions. Each subject listened monaurally to three randomizations of the NU No. 6 word lists $(1,2,3, \& 4)$ at three compression ratios $(45 \%, 65 \%, \& 75 \%)$ presented at 5 levels in $10 \mathrm{~dB}$ increments (at $45 \%$ compression ratio: $30,40,50,60, \& 70 \mathrm{~dB}$ SPL; at $65 \%$ compression ratio: $35,45,55,65, \& 75 \mathrm{~dB}$ SPL; \& at $75 \%$ compression ratio: 50, $60,70,80, \& 90 \mathrm{~dB}$ SPL). The mean and standard deviation data for each compression ratio condition (45\%, 65\% \& 75\%) for the corresponding presentation levels are presented in Table 5 and Figure 4. Mean percent correct recognition for the $45 \%$ compression ratio ranged from 4.98 at $30 \mathrm{~dB}$ SPL to $92.1 \%$ at $70 \mathrm{~dB}$ SPL with corresponding standard deviations of 3.8 and 5.2 respectively. At the $65 \%$ compression ratio, mean percent correct recognition ranged from $5.9 \%$ at $35 \mathrm{~dB}$ SPL to $73.4 \%$ at $75 \mathrm{~dB}$ SPL with corresponding standard deviations of 4.9 and 13.4 respectively. Mean percent correct recognition for the $75 \%$ compression ratio ranged from 19.4 at $50 \mathrm{~dB}$ SPL to 40.4 at $90 \mathrm{~dB}$ SPL. Standard deviations were 12.4 and 11.6 respectively. The individual subject percent correct recognition data for Experiment II can be found in Appendix D. 
Table 5

Mean and standard Deviation Data for each Comoression Ratio condition with the corresponding sound pressure Levels for Experiment II.

\begin{tabular}{|c|c|c|c|c|c|c|}
\hline \multirow{2}{*}{$\begin{array}{c}\text { Compression } \\
\text { Ratio }\end{array}$} & & \multicolumn{5}{|c|}{ Sound Pressure Level } \\
\hline & & 30 & 40 & 50 & 60 & 70 \\
\hline $45 \%$ & $\begin{array}{l}\text { Mean } \\
\text { STD }\end{array}$ & $\begin{array}{l}4.9 \\
3.8\end{array}$ & $\begin{array}{l}34.9 \\
12.9\end{array}$ & $\begin{array}{l}67.8 \\
14.1\end{array}$ & $\begin{array}{r}82.2 \\
9.4\end{array}$ & $\begin{array}{r}92.1 \\
5.2\end{array}$ \\
\hline & & 35 & 45 & 55 & 65 & 75 \\
\hline $65 \%$ & $\begin{array}{l}\text { Mean } \\
\text { STD }\end{array}$ & $\begin{array}{l}5.9 \\
4.9\end{array}$ & $\begin{array}{l}31.89 \\
16.7\end{array}$ & $\begin{array}{l}57.7 \\
14.2\end{array}$ & $\begin{array}{l}71.2 \\
11.7\end{array}$ & $\begin{array}{l}73.4 \\
13.4\end{array}$ \\
\hline & & 50 & 60 & 70 & 80 & 90 \\
\hline $75 \%$ & $\begin{array}{l}\text { Mean } \\
\text { STD }\end{array}$ & $\begin{array}{l}19.4 \\
12.4\end{array}$ & $\begin{array}{l}34.6 \\
18.7\end{array}$ & $\begin{array}{l}47.2 \\
12.2\end{array}$ & $\begin{array}{l}49.1 \\
13.5\end{array}$ & $\begin{array}{l}40.4 \\
11.6\end{array}$ \\
\hline
\end{tabular}




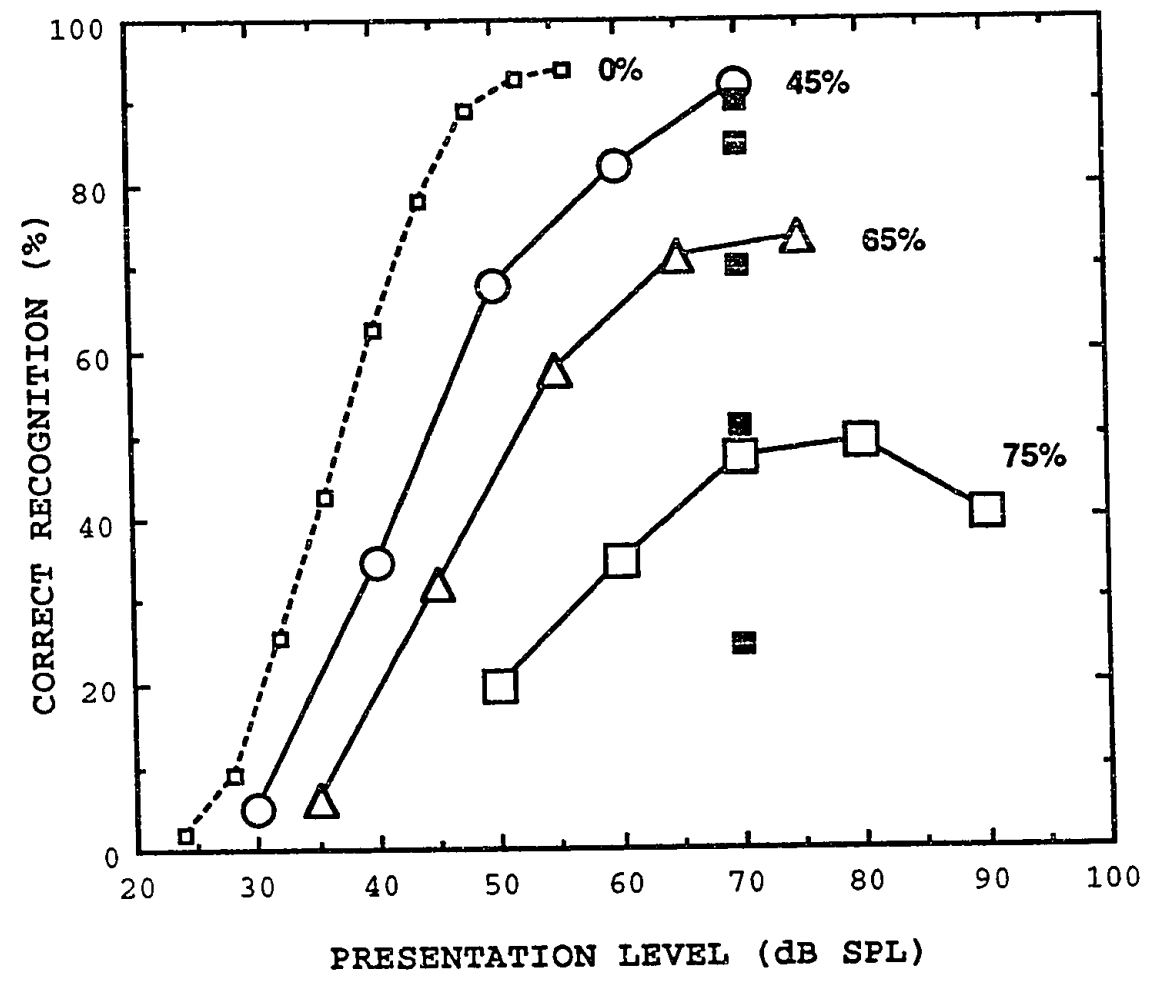

FIGURE 4. Mean percent correct recognition for the three compression ratio conditions in Experiment II. For reference, the unaltered N.U.No.6 function (0\%) from wilson, Zizz, Shanks, and Causey (1990) is shown along with the data from Experiment $I$. 
The resuits indicated that as the presentation level increased, word-recognition performance increased for each of the three compression ratios except at the $75 \%$ compression ratio condition, for which maximum word-recognition performance was achieved at $70 \mathrm{~dB}$ SPL. For each separate compression ratio condition (45\% 65\% \& 75\%) a significant increase in mean percent correct recognition performance resulted as a function of increased presentation level with the exception of the following two conditions: 1) at the 65\% compression ratio for the interval between 65-75 dB $(\underline{t}(34)=.53, \underline{p} . \leq .05)$ (however, a significant increase in mean percent word-recognition performance was found for the interval of $55-75 \mathrm{~dB} \operatorname{SPL}(t(34)=3.42, \underline{D} . \leq .05)$ and; 2$)$ at the 75\% compression ratio for the interval of 70-80 dB SPL $(t(34)=.44,2 . \leq .05)$. Further analysis of the $75 \%$ compression ratio revealed that a significant "decrease" in percent correct recognition occurred between 70-90 dB SPL $(t(34)=1.71, \mathbb{D} . \leq .05)$.

Figure 4 displays the mean percent correct recognition data for each compression ratio condition (45\%, 65\%, \& 75\%) for Experiment II as a function of sound pressure level. The results for Experiment I (represented by filled squares) also are depicted. In addition, the unaltered psychometric function for the NU No. 6 test is presented (wilson et al.. 1990). As the compression ratio increased from $45 \%$ to $75 \%$ the mean percent correct recognition data decreased further 
from the unaltered function of the NU No. 6 test. Therefore, the function for the $45 \%$ compression ratio was found to be similar to the unaltered NU No. 6 function when sufficient sound pressure levels were presented. However, at higher compression ratios, sound pressure level increases did not eliminate the effects of time compression. In addition, for the compression ratio of $75 \%$, mean percent correct performance was not stable (performance deteriorated at the highest sound pressure level). Consequently, the results indicate that for use in a clinical setting the compression ratio of $65 \%$ should be utilized.

The general pattern of increased word-recognition performance with increased presentation level is consistent with previous studies that have reported normative data for time-compressed NU No. 6 words (Beasley et. al, 1972a; Beasley et al., 1972b; Rienshce et al., 1976). A comparison of the results of the current investigation to the study of Beasley et al. (1972a) revealed contradictory results; wordrecognition performance appeared to be similar at the $45 \%$ compression ratio, yet differed at the 65\% compression ratio condition. For example, Beasley et al. (1972a) reported mean percent correct scores for the $40 \%$ and $60 \%$ compression ratio conditions to be $88.6 \%$ and $83.6 \%$ (presented at 24 dB above SRT) respectively. The corresponding data from the current study were $92.1 \%$ and $73.4 \%$ at the $45 \%$ and $65 \%$ compression ratios presented at "approximate" presentation levels $(70$ and 
$75 \mathrm{~dB}$ SPL respectively). The presentation levels for the comparison were chosen according to data from wilson et al. (1990); these researchers described the psychometric functions generated by the male (Rintelmann, 1974) and female recordings for unaltered NU-6 materials. Wilson et al. found that equal performance levels for the two versions of the unaltered NU-6 materials were obtained when the female recordings were presented at sound pressure levels of 5 to $15 \mathrm{~dB}$ higher presentation levels relative to the presenation levels for the male recording. The discrepancy between the data at the $65 \%$ compression ratio condition may be a result of the compression process differently effecting the NU-6 speech materials spoken by different speakers. Consequently, the relationship between the unaltered NU-6 materials for different speakers may not be maintained for the compressed versions of the same materials.

Data similar to the Beasley et al. (1972a) study also was reported by Beasley et al. (1972b) and Rienshie et al. (1976). A conclusionary statement, however, about the difference in mean word-recognition between this investigation and the Beasley study as well as other studies that have reported similar results as Beasley et al. (1972a) cannot be made due to the fact that different research designs and parameters were utilized.

Figure 4 also demonstrates that as the compression ratio increased from $45 \%$ to $75 \%$ there was less correlation between 
the mean correct percent recognition data for the two experiments. Statistical analysis revealed significantly poorer percent correct recognition data for Experiment I compared to Experiment II for the $75 \%$ compression ratio condition $(\underline{E}(32)=4.1, \underline{D} . \leq .05)$. The reason for the significantly different scores between the two experiments may be attributed an increased learning effect experienced by the subjects in the second experiment.

In order to illustrate the learning effect produced in Experiment II mean percent correct data is displayed by compression ratio order of presentation (see Figure 5). The three different graphs depict the three compression ratio conditons $(45 \%, 65 \%$ \& 75\%). Group one (represented by squares) represents the first presentation of the compression ratio; group two (represented by triangles) represents the second presentation of that specific compression ratio; group three (represented by circles) represents the third presentation of that same compression ratio. For each level of compression the third presentation (group three) resulted in significantly better word-recognition relative to the first presentation (group one) for all of the compression ratio conditions (at $75 \% t(11)=4.2, \underline{2} . \leq .05$; at $65 \%$ $t(11)=4.9, \mathfrak{R} . \leq .05)$ except at the $45 \%$ compression ratio condition (at $70 \mathrm{~dB}$ SPL) for which no signifcant difference was found $(\underline{t}(11)=.1, \underline{D} . \leq .05)$. Moreover, the most significant learning effects were found for the highest 


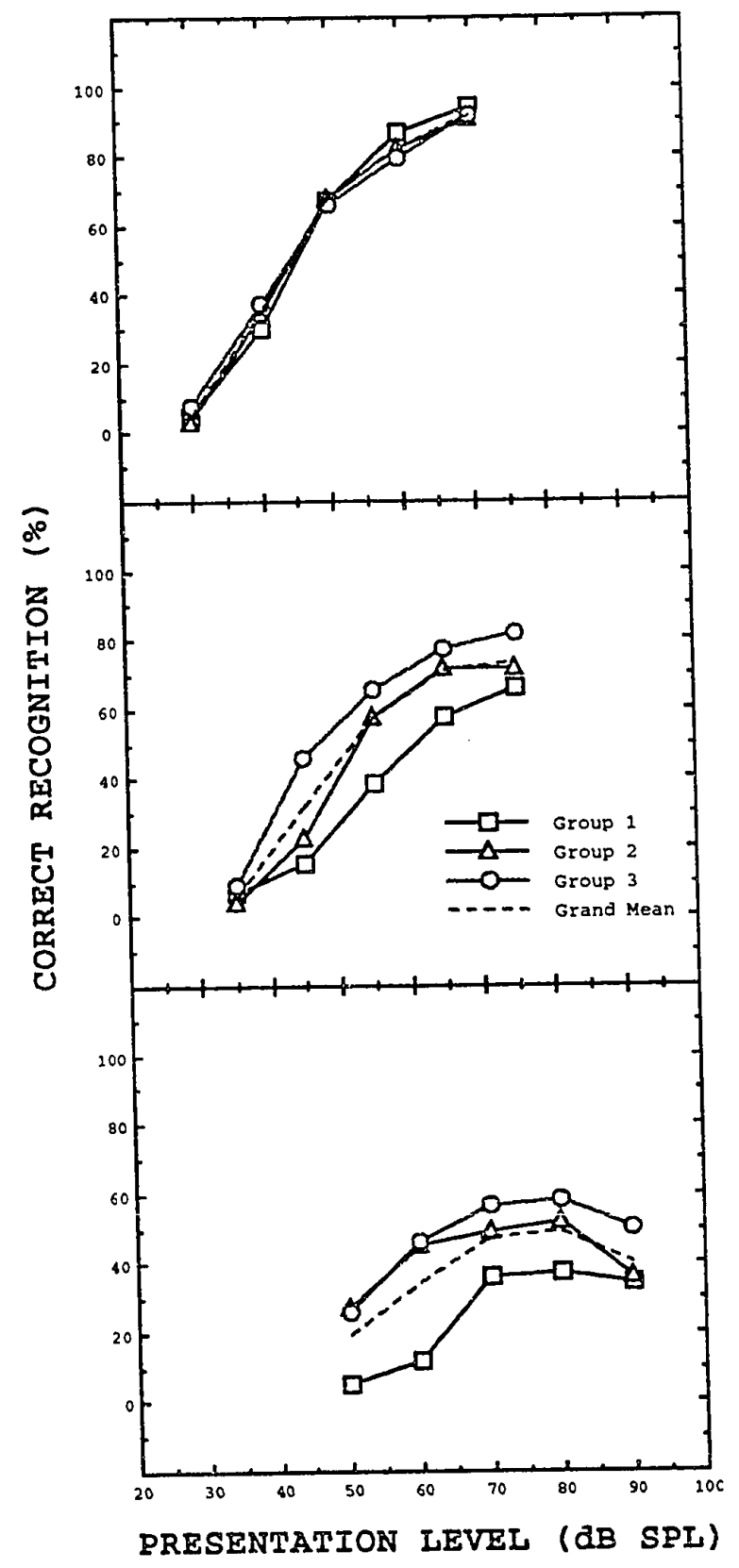

FIGURE 5. Mean percent correct data from Experiment II. Group 1 (squares), Group 2 (triangles), and Group 3 (circles) correspond to the first, second, and third presentation of each compression condition. 
compression ratio utilized (75\%) and the least learning effects were found at the $45 \%$ compression ratio condition.

Further analysis of the first and second order of presentation was conducted for the $65 \%$ compression ratio condition at a presentation level of $75 \mathrm{~dB}$ SPL. The results indicated that there was not a significant difference $(t(11)=.9, \mathbb{D} . \leq .05)$ between the first and second presentations of the compressed NU No. 6 word lists. clinically, these data suggest that for two presentations of time-compressed NU-6 word lists presented at the $65 \%$ compression ratio condition (at a level of 75 dB SPL) should result in minimal learning effects for normal-hearing listeners. These data are in good agreement with the Grimes et al. (1984) data that found no significant difference between the first and second presentations of compressed NU No. 6 words presented at a presentation level of $32 \mathrm{~dB}$ (above $\mathrm{SRT}$ ) for the $60 \%$ compression ratio condition. Finally, a target word analysis of Lists 1 and 4 was conducted. The percent correct recognition for each target word was tabulated for the five compression levels utilized in Experiment I presented at $70 \mathrm{~dB}$ SPL (see Appendix E). The words most consistently missed among all the compression ratio conditions were: "death, king, raise, lot, sell, yearn, join, ripe and should."

Error analysis of the most commonly missed words revealed that $50 \%$ of the errors invovled vowel substitutions. 
For example, the word "lot" was most often identified as "Iit"; the word "yearn" was most often replaced by the word "here"; the word "king" was most often replaced by the word "cane"; and finally, the word "should" was most often identified as "short." Four words were misidentified due to vowel substitutions; two of these substitution errors involved a short vowel substitution for a long or medium length vowel. This pattern of vowel substitution is consistent with findings of Daniloff, Shriner, and zemlin (1968) who examined effects of time compression on the perception of vowels (placed in a /h_d/ phonemic context) for normal-hearing listeners. One possible explanation as to why vowel substitution errors were made has to do with the vowel duration. It may be that the duration of an unaltered "short" vowel may be similar to the duration of a timecompressed "medium" or "long" vowel and therefore the listeners recognize the speech stimulus as a short vowel. This concept is similar to the principle of reduction which states that increased speaking rate can alter the articulation of vowels so that long vowels change in the direction of lax vowels (Kent, 1988).

Examination of the consonant errors included analyzing the acoustical features of phonemes, duration, frequency of spectra, and intensity as well as the examination of place, manner and voicing properties. The majority of consonant errors involved the phonemes $/ \mathrm{n} /, / \mathrm{ng} /, / \mathrm{y} /$, and $/ \mathrm{p} /$. 
Similar to vowels, these phonemes have spectrums that consist of low frequency energy. Therefore, the results indicate that the compression process may interfere with the perception of phonemes with low frequency dominant spectra. The remaining consonant errors were attributed to typical voicing errors. For example, the /d/ in "should" was most often replaced by $/ t /$; the $/ z /$ in "raise" was most often replaced by /s/. Finally, /th/ in "death" was most often replaced by /f/ which may be attributed the fact the speech stimuli were presented auditorally, with no opportunities for visual clues.

Summary

The results indicated that increasing amounts of compression resulted in corresponding decreases in wordrecognition performance. In addition, it was found that increases in sound pressure level directly contributed to better word-recognition performance, moreover, this relationship was most evident at the $45 \%$ compression ratio ccondition and less apparent with higher compression ratios. The most stable word-recognition scores were obtained from NU No. 6 word lists presented at the compression ratio of $65 \%$. Furthermore, two presentations of time-compressed NU No. 6 word lists presented at the $65 \%$ compression ratio condition at a presentation level of $75 \mathrm{~dB}$ SPL resulted in minimal learning effects for normal-hearing listeners. Additionally, Lists 1 and 4 were found to be equivalent at the 65\% 
compression ratio condition. In analyzing the results it was found that a score of $53 \%$ or better would be considered clinically normal for the NU No. 6 word lists ( 1 \& 4) presented at a compression ratio of $65 \%$ at a presentation level of $70 \mathrm{~dB}$ SPL. Finaliy, the results of the error analysis suggest that phonemes with low frequency dominant spectra may be more susceptible to the time compression process than other phonemes. 


\section{CHAPTER V}

\section{SURMARY}

Time-compressed speech materials are utilized in the evaluation of auditory perceptual disorders. Specifically, compressed speech materials are employed to detect the breakdown of auditory processing and to describe and quantify functional auditory ability. The results of these tests can be used to determine appropriate remediation and to monitor recovery of auditory perceptual functioning (Mueller, Sedge, \& Salazar, 1986).

In the past, techniques utilized to produce the temporal alterations in the speech signal were limited by factoris such as frequency distortion, amplitude modulation, and the inability to control the compression process relative to the linguistic content of the speech signal. Furthermore, until the advent of computerized techniques, researchers did not attempt to verify the amount of compression that resulted from these earlier techniques. Digital processing techniques accomplish the alteration in the speech signal without the problems associated with earlier methods of producing timecompressed speech, and consequently are the most efficient method of producing time-compressed speech materials.

\section{clinical Implications}

The results of this investigation indicated the digital processing technique utilized in this study is a valid method 
of producing time-compressed speech materials. Moreover, the results of the current study provided normative data for word-recognition performance for a ditigally compressed version of the NU No. 6 test (utilizing a female speaker) for normal-hearing adults. These data can be utilized in the evaluation of auditory processing disorders for normalhearing adults. Word-recognition scores of $53 \%$ or better would be considered clinically normal for NU No. 6 word lists ( $1 \& 4)$ compressed at the 65\% ratio condition for a presentation level of $70 \mathrm{~dB}$ SPL.

\section{Future Research}

Future research should include the examination of interlist equivalency for List 2 and 3 of the NU No. 6 word lists considering the fact that previous research lGrimes et al., 1984) has suggested that the determination of interaural differences may be contaminated by presenting two lists with unequal standard deviations (in which case Grimes et al. recommend that the list with the largest standard deviation should be used). Moreover, the validity of the digitally compressed NU No. 6 Auditory Test needs to be investigated for patients with auditory perceptual disorders. Further, the reliability should be examined with multiple follow-up studies of patients with diagnosed auditory perceptual disorders. High frequency hearing sensitivity also has been reported to influence the results of compressed speech tests (Grimes, et al., 1984). Therefore, research with hearing- 
impaired listeners should be conducted. Finally, future research should focus on establishing normative data for the digitally compressed speech materials with children. 


\section{References}




\section{References}

Beasley, D., Forman, B., \& Rintelmann, W. (1972b). Perception of time-compressed CNC monosyllables by normal listeners. Journal of Auditory Research, 12, 71-75.

Beasley, D., Schwimmer, S., \& Rintelmann, W. (1972a). Intelligibility of time-comoressed CNC monosyllables. Journal of Speech and Hearing Research, 15, 340-350.

Beasley, D. \& Shriner, T. (1973). Auditory analysis of temporally distorted sequential approximations. Journal of Auditory communication, 12, 262-271.

Beattie, Edgerton, \& Svihovec, (1977). A comparison of the Auditec of St. Loius cassette recording of NU-6 and CID W22 on a normal-hearing population. Journal of Speech and Hearing Disorders, $\underline{42}, 60-64$.

kent, R. (1988). Normal aspects of Articulation. In J. Bernthal, \& W. Bankson (Eds.), Articulation and phonological disorders (pp. 5-60). New Jersey: PrenticeHall, Inc.

Cambron, N., Wilson, R., \& Shanks, J. (1991). Spondiac word detection and recognition functions for female and male speakers. Behavioral Audiology, 12, 64-69.

Calearo, C., \& Lazzaroni, A. (1957). Speech intelligibility in relation to the speed of the message. Laryngoscope, $410-419$.

Daniloff, G., Shriner, T., \& Zemlin, W. (1968). Intelligibility of vowels altered in duration and frequency. The Journal of the Acoustical Society of America, 44, 700-707.

De Chicchis, A., Orchik, D., \& Tecca, J. (1981). The effect of word list and talker variation on word-recognition scores using time-altered speech. Journal of speech and Hearing Disorders, 46, 213-216. 
Diel, C., White, R., \& Burk, K. (1959). Rate and communication speech monographs. In $\mathrm{S}$. Duker, (Ed.), Time-compressed speech; An anthology and bibliography in three volumes, (pp. 75-77) volume 1, New Jersey: Scarecrow Press, Inc.

Fairbanks, G., Everitt, W., \& Jaeger, R. (1954a). Methods for time or frequency compression-expansion of speech. Transactions of $I, R, E, 2,7-12$.

Fairbanks, G., \& Kodman, F. (1957b). Word intelligibility as a function of time compression. Journal of the Acoustical Society of America, 29, 636-641.

Garvey, W., (1953) The intelligibility of speeded speech. ouarterly Journal of Speech, 39, 296-306.

Goldstein, H. (1949). Reading and listening comprehension at various controlled rates. In S. Duker, (Ed.), Timecompressed speech: An anthology and bibliography in three volumes (pp. 78-92). Volume 1, New Jersey: Scarecrow Press, Inc.

Grimes, A.. Mueller, G., \& Williams, D. (1984). Clinical considerations in the use of time-compressed speech. Ear and Hearing, 5, 114-117.

Klummp, R. \& Webster, J. (1961). Intelligibility of timecompressed speech. Journal of the Acoustical Society of America, 33, 265-267.

Lass, N., Riensche, L., \& Beasley, D. (1984). Applications of time altered speech in speech-language pathology and audiology. Communicative Disorders, 2, 19-31.

Lee, F. (1972). Time compression and expansion of speech by the sampling method. Journal of the Audic Engineering Society, 738-742.

Maki, J., Beasley, D. (1976). Time and frequency altered. speech. In contemporary issues in experimental phonetics (pp. 419-457) New York: Academic Press, Inc.

Matkin, D., (1983) Multidisciplinary approach to central auditory evaluations. In central auditory processing disorders: Problems of speech, lanquage and learning (pp. 223-242). Baltimore: University Park Press. 
Mueller, H. Sedge, R., \& Salazar, A. (1986). Auditory assessment of neural trauma. In Neurotrauma: treatment, rehabilitation and related issues (pp. 155-158). Boston: Butterworths.

Riensche, L., Konkle, D., \& Beasley, D. (1976). Discrimination of time-compressed CNC monosyllables for normal listeners. Journal of Auditory Research, 16, 98-101.

Rintelmann, W., \& Associates (1974). Six experiments on speech discrimination utilizing CNC monosyllables (Northwestern University Auditory Test No. 6). Journal of Auditory Research, 2., 118-129.

Rintelmann, W., \& Jetty, A. (1968). Unpublished manuscript, Michigan state University.

Silman, S., \& Silverman, C. (1991). Central Auditory Speech Tests. In Auditory diagnosis: Principles and applications (pp. 216-245). San Diego: Academic Press Inc.

Steinberg, E. (1936). Effects of distortion on speech and music. In S. Duker, (Ed.), Time-comoressed speech: An anthologv and bibliography in three volumes (pp. 932-938). volume 1, New Jersey: Scarecrow Press, Inc.

Wilson, R., Preece, J., Salamon, D., Sperry, J., \& Bornstein, S. (1993). Effects of time compression and time compression plus reverberation on the intelligibility of Northwestern University Auditory Test No. 6. Manuscript submitted for publication.

Wilson, R., Zizz, C., Shanks, J., \& Causey, G. (1990). Normative data in quiet, broadband noise, and competing message for Northwestern University Auditory Test No. 6 by a female speaker. Journal of Speech and Hearing Disorders, 55, 771-778. 
APPENDICES 
Appendix A

Duration in Milliseconds of the Unaltered (0\%) Speech Files and the corresponding Percent of Compression.

NU No. 6, word List 1.

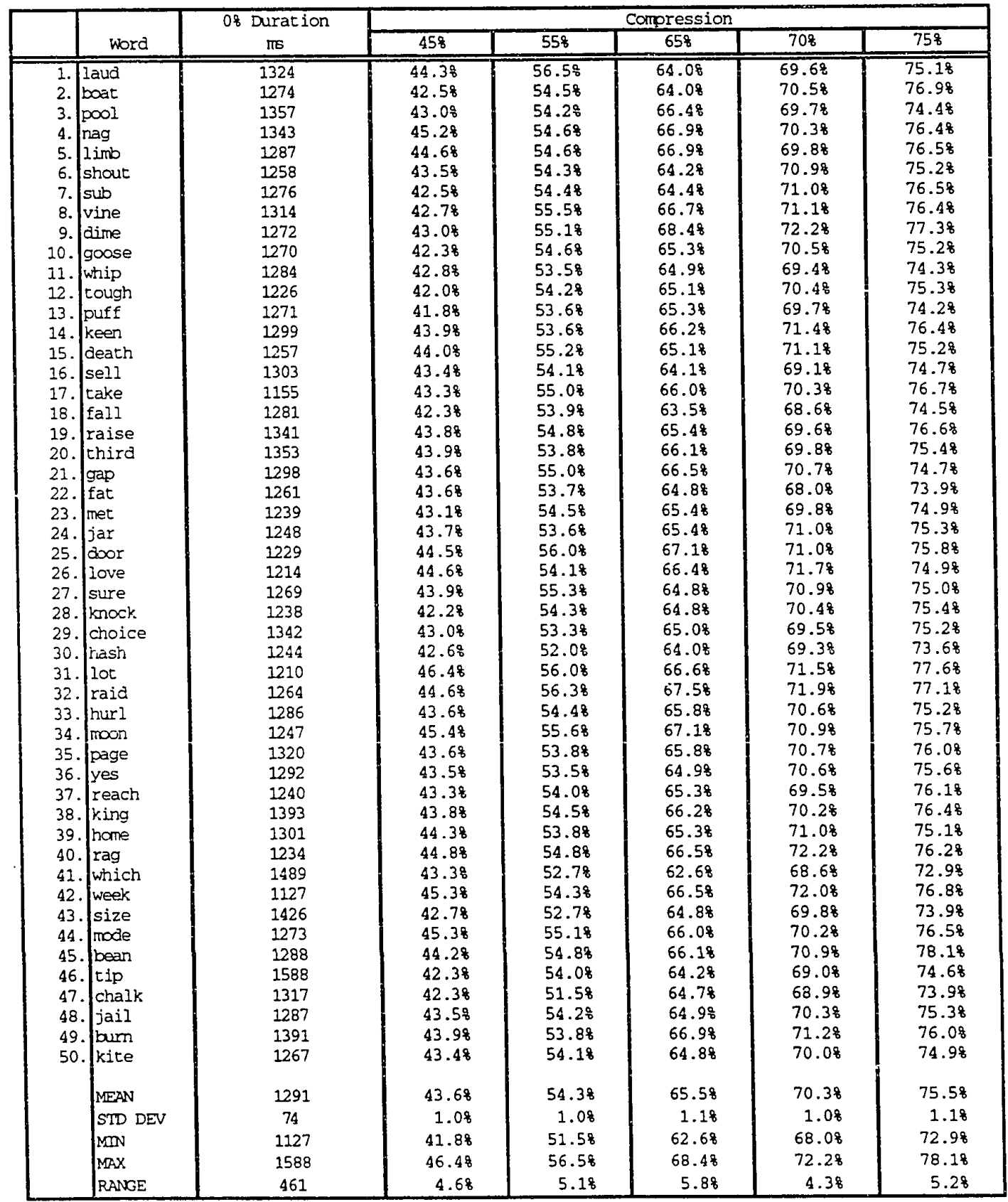


Appendix A Cont.

NU No. 6, Word List 2

\begin{tabular}{|c|c|c|c|c|c|}
\hline & \multirow[b]{2}{*}{ word } & \multirow{2}{*}{$\begin{array}{c}08 \text { Duration } \\
\mathrm{ms}\end{array}$} & & Compression & \multirow[b]{2}{*}{758} \\
\hline & & & 458 & 658 & \\
\hline & pick & 1202 & 44.18 & 69.28 & 76.68 \\
\hline 2. & $\begin{array}{l}\text { room } \\
\text { nice }\end{array}$ & $\begin{array}{l}1217 \\
1325\end{array}$ & 45.48 & 69.18 & 79.68 \\
\hline 4. & $\begin{array}{l}\text { nice } \\
\text { said }\end{array}$ & $\begin{array}{l}1325 \\
1281\end{array}$ & $\begin{array}{l}43.88 \\
44.28\end{array}$ & $\begin{array}{l}67.88 \\
66.98\end{array}$ & $\begin{array}{l}76.18 \\
75.38\end{array}$ \\
\hline 5. & fail & 1262 & 43.78 & 67.78 & $\begin{array}{l}75.3 \% \\
76.88\end{array}$ \\
\hline 6. & south & 1260 & 43.38 & 66.38 & 76.58 \\
\hline 7. & white & 1325 & 43.48 & 65.68 & 75.68 \\
\hline 8. & keep & 1322 & 43.48 & 66.58 & 77.08 \\
\hline $\begin{array}{r}9 . \\
10 .\end{array}$ & dead & 1207 & 45.48 & 66.48 & 78.98 \\
\hline $\begin{array}{l}10 . \\
11 .\end{array}$ & $\begin{array}{l}\text { loaf } \\
\text { dab }\end{array}$ & $\begin{array}{l}1198 \\
1407\end{array}$ & 44.38 & 66.68 & 77.08 \\
\hline $\begin{array}{l}11 . \\
12 .\end{array}$ & $\begin{array}{l}a a b \\
m m b\end{array}$ & $\begin{array}{l}1407 \\
1205\end{array}$ & $\begin{array}{l}44.88 \\
45.18\end{array}$ & $\begin{array}{l}66.88 \\
67.38\end{array}$ & 77.58 \\
\hline 13. & juice & 1294 & 43.38 & 66.48 & $\begin{array}{l}77.28 \\
76.58\end{array}$ \\
\hline 14. & chief & 1269 & 43.58 & 65.38 & 76.48 \\
\hline $\begin{array}{l}15 . \\
16 .\end{array}$ & merge & 1233 & 45.18 & 67.28 & 76.68 \\
\hline $\begin{array}{l}16 . \\
17 .\end{array}$ & $\begin{array}{l}\text { wag } \\
\text { rain }\end{array}$ & 1285 & 46.78 & 65.88 & 77.78 \\
\hline 18. & $\begin{array}{l}\text { rain } \\
\text { witch }\end{array}$ & $\begin{array}{l}1253 \\
1201\end{array}$ & $\begin{array}{l}44.38 \\
43.08\end{array}$ & 67.28 & 78.08 \\
\hline 19. & soap & $\begin{array}{l}1201 \\
1164\end{array}$ & $\begin{array}{l}43.08 \\
43.68\end{array}$ & $\begin{array}{l}65.98 \\
66.88\end{array}$ & 75.88 \\
\hline 20. & young & 1173 & 45.98 & $\begin{array}{l}66.88 \\
66.58\end{array}$ & $\begin{array}{l}76.98 \\
77.28\end{array}$ \\
\hline 21. & $\operatorname{con}$ & 1193 & 45.58 & 65.78 & 77.38 \\
\hline 22 . & keg & 1205 & 45.48 & 66.68 & 77.08 \\
\hline $\begin{array}{l}23 . \\
24 .\end{array}$ & calm & 1201 & 45.38 & 66.78 & 77.88 \\
\hline $\begin{array}{l}24 . \\
25 .\end{array}$ & $\begin{array}{l}\text { tool } \\
\text { pike }\end{array}$ & $\begin{array}{l}1203 \\
1146\end{array}$ & 44.98 & 66.68 & 76.98 \\
\hline 26. & $\begin{array}{l}\text { pike } \\
\text { mill }\end{array}$ & $\begin{array}{l}1146 \\
1107\end{array}$ & $\begin{array}{l}43.78 \\
45.88\end{array}$ & $\begin{array}{l}67.48 \\
67.98\end{array}$ & $\begin{array}{l}76.68 \\
78.38\end{array}$ \\
\hline 27. & hush & 1183 & 43.38 & 64.58 & $\begin{array}{l}78.38 \\
75.08\end{array}$ \\
\hline 28. & shack & 1180 & 43.78 & 65.38 & 75.68 \\
\hline 29 . & read & 1149 & 44.28 & 67.48 & 76.48 \\
\hline 30. & rot & 1123 & 44.28 & 66.58 & 76.28 \\
\hline 31. & hate & 1083 & 45.48 & $\begin{array}{l}66.48 \\
66.38\end{array}$ & 76.68 \\
\hline $\begin{array}{l}32 . \\
33 .\end{array}$ & $\begin{array}{l}\text { live } \\
\text { book }\end{array}$ & $\begin{array}{l}1179 \\
1124\end{array}$ & $\begin{array}{l}45.28 \\
45.78\end{array}$ & $\begin{array}{l}66.38 \\
66.98\end{array}$ & $\begin{array}{l}76.68 \\
77.38\end{array}$ \\
\hline 34. & $\begin{array}{l}\text { book } \\
\text { voice }\end{array}$ & $\begin{array}{l}1124 \\
1238\end{array}$ & 43.68 & 65.28 & 77.38 \\
\hline 35 . & gaze & 1197 & 44.58 & 66.58 & 77.08 \\
\hline 36. & pad & 1231 & 45.08 & 66.98 & 77.28 \\
\hline 37. & thought & 1195 & 44.18 & 67.18 & 77.08 \\
\hline 38. & bought & 1174 & 46.38 & 66.78 & 76.48 \\
\hline 39. & tum & 1306 & 46.08 & 66.58 & 68.48 \\
\hline 40. & chair & 1264 & 46.78 & 65.78 & 78.58 \\
\hline 41. & lore & 1108 & 45.58 & 66.58 & 77.78 \\
\hline 42 . & bite & 1131 & 44.58 & 65.58 & 77.48 \\
\hline 43. & haze & 1233 & 43.88 & 65.78 & 76.18 \\
\hline 44. & match & 1259 & 43.98 & $65.7 \%$ & 75.78 \\
\hline 45. & learn & 1199 & 44.78 & 67.38 & 78.68 \\
\hline 46. & shawl & 1387 & 43.38 & 65.38 & 75.18 \\
\hline 47. & deep & 1374 & 43.68 & 66.58 & 75.78 \\
\hline 48. & gin & 1231 & 47.08 & 66.38 & 77.28 \\
\hline 49. & goal & 1445 & 47.88 & 65.98 & 76.78 \\
\hline 50. & far & 1173 & 45.58 & 67.58 & 74.98 \\
\hline & MEAN & 1226 & 44.78 & 66.68 & $76.7 \%$ \\
\hline & STD DEV & 78 & 1.18 & 0.98 & $1.5 \%$ \\
\hline & MEN & 1083 & 43.08 & 64.58 & 68.48 \\
\hline & MAX & 1445 & $47.8 \%$ & 69.28 & 79.68 \\
\hline & RANGE & 362 & 4.98 & 4.78 & 11.28 \\
\hline
\end{tabular}


Appendix A Cont.

NU No. 6, Word List 3

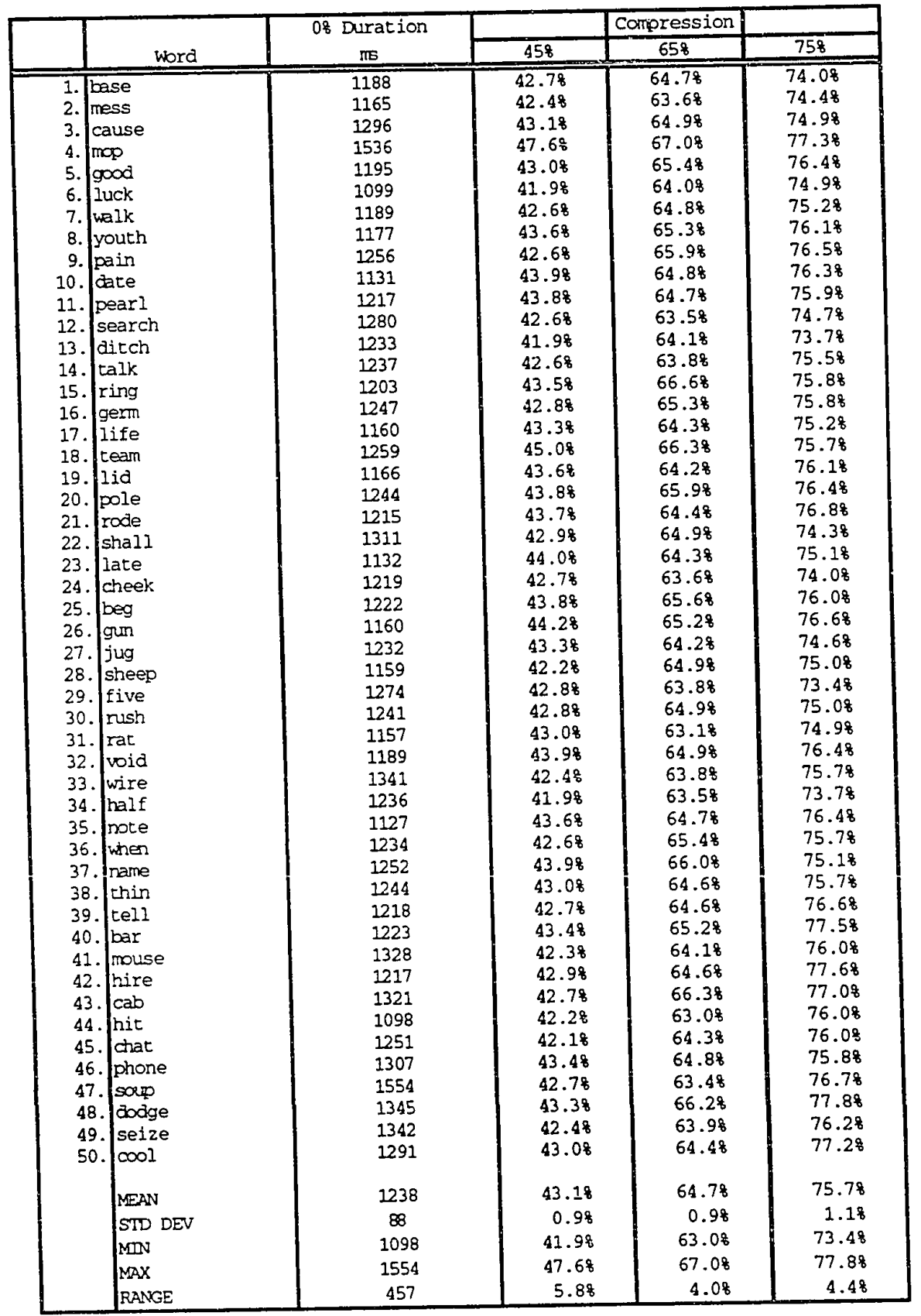


Appendix A Cont.

NU No. 6, word List 4

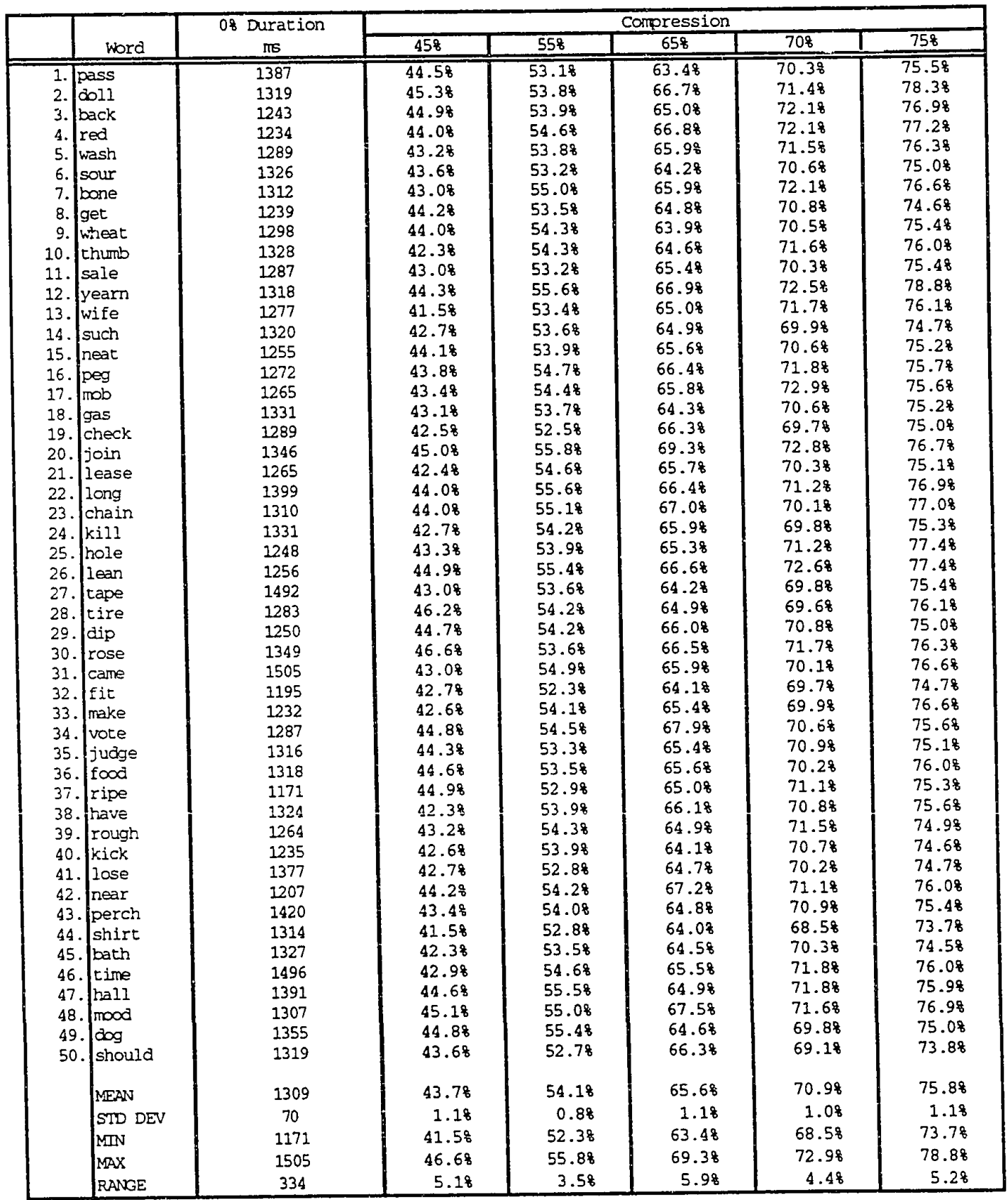




\section{Appendix B}

Randomizations of the NU No. 6 Word Lists and

Compression Conditions used for Experiment II.

Subject

List Randomizations

1. $\mathrm{ABC}$

A3 (12431)

B1 (23142)

C1 (41234)

2. $A C B$

AI (42134)

C2 (24312)

B2 (31243)

3. $B A C$

B3 (14231)

A.2 (21432)

C3 (34123)

4. $\mathrm{BCA}$

BI (23142)

C1 (41234)

A3 (12431)

5. $\mathrm{CAB}$

C2 (24312)

A1 (42134)

B2 (31243)

6. $\mathrm{CBA}$

C3 (34123)

B3 (14231)

A2 (21432)

7. $\mathrm{ABC}$

A3 (1243I)

BI (23142)

C1 (41234)

8. $\mathrm{ACB}$

A1 (42134)

C2(24312)

B2 (31243)

9. $B A C$

B3 (14231)

A2 (21432)

C3 (34123)

10. $B C A$

B1 (23142)

CI (41234)

A3 (12431)

11. $\mathrm{CAB}$

C2 (24312)

AI (42134)

B2 (31243)

12. CBA

C3 (34123)

B3 (14231)

F2 (21432)

13. $A B C$

A3 (12431)

B1 (23142)

C1 (41234)

14. $\mathrm{ACB}$

AI (42134)

C2 (24312)

B2 (31243)

15. BAC

B3 (14231)

A2 (21432)

C3 (34123)

16. $\mathrm{BCA}$

$B 1(23142)$

C1 $(41234)$

A.3 (12431)

17. $\mathrm{CAB}$

$\mathrm{C} 2(24312)$

A1 (42134)

B2 (31243)

18. CBA

C3 (34123)

B3 (14231)

A2 (21432)

Note: A, B, C represent compression ratio conditions of $45 \%, 65 \%$ and $75 \%$ respectively. 
Appendix B. Cont.

Subject and List Randomization Grouped by First, Second and Third Presentations of Compression Ratio Condition for Experiment II.

\begin{tabular}{|c|c|c|c|c|c|c|c|}
\hline $75 \%$ & LIST & \multicolumn{3}{|c|}{ SUBJECT } & \multicolumn{3}{|c|}{ NUMBER } \\
\hline AI & 4213 & 2 & 5 & 8 & 11 & 14 & 17 \\
\hline $\mathrm{A} 2$ & 2143 & 3 & 6 & 9 & 12 & 15 & 18 \\
\hline A3 & 1243 & 1 & 4 & 7 & 10 & 13 & 16 \\
\hline $65 \%$ & & & & & & & \\
\hline B1 & 2314 & 1 & 4 & 7 & 10 & 13 & 16 \\
\hline B2 & 3124 & 2 & 5 & 8 & 11 & 14 & 17 \\
\hline B3 & 1423 & 3 & 6 & 9 & 12 & 15 & 18 \\
\hline
\end{tabular}

$45 \%$

$\begin{array}{llllllll}\text { C1 } & 4123 & 1 & 4 & 7 & 10 & 13 & 16 \\ \text { C2 } & 2431 & 2 & 5 & 8 & 11 & 14 & 17 \\ \text { C3 } & 3412 & 3 & 6 & 9 & 12 & 15 & 18\end{array}$

Note: A, B, C represent compression ratio conditions of $45 \%, 65 \%$ and $75 \%$ respectively. 
Appendix C

The Individual Subject Correct Recognition Scores (in Percent Correct) for NU No. 6 List 1 for the Five Compression Ratios Presented at $70 \mathrm{~dB}$ SPL for Experiment $I$.

\begin{tabular}{|c|c|c|c|c|c|}
\hline \multirow{2}{*}{ Subject } & \multicolumn{5}{|c|}{ Nominal Compression Ratio $(8)$} \\
\hline & 45 & 55 & 65 & 70 & 75 \\
\hline 1. & 86 & 88 & 60 & 52 & 16 \\
2. & 98 & 90 & 86 & 78 & 48 \\
3. & 88 & 84 & 66 & 44 & 18 \\
4. & 88 & 88 & 80 & 72 & 54 \\
5. & 88 & 80 & 48 & 32 & 26 \\
6. & 88 & 82 & 80 & 52 & 24 \\
7. & 86 & 82 & 62 & 44 & 4 \\
8. & 86 & 76 & 54 & 34 & 16 \\
9. & 86 & 84 & 70 & 46 & 8 \\
10. & 92 & 84 & 62 & 56 & 14 \\
11. & 92 & 88 & 76 & 62 & 28 \\
12. & 96 & 98 & 78 & 62 & 18 \\
13. & 90 & 78 & 64 & 32 & 14 \\
14. & 90 & 78 & 70 & 30 & 12 \\
15. & 84 & 80 & 66 & 36 & 24 \\
16. & 82 & 80 & 76 & 62 & 32 \\
& & & & & \\
MEAN & 88.7 & 83.7 & 68.6 & 49.6 & 22 \\
ST DEV & 4.2 & 5.6 & 10.3 & 14.9 & 13 \\
MIN & 82 & 76 & 48 & 30 & 4 \\
MAX & 98 & 98 & 86 & 78 & 54 \\
RANGE & 16 & 22 & 38 & 48 & 50 \\
\hline
\end{tabular}


Appendix C

The Individual Subject correct Recognition Scores (in Percent Correct) for NU No. 6 List 4 for the Five Compression Ratios Presented at $70 \mathrm{~dB}$ SPL for Experiment $I$.

\begin{tabular}{|c|c|c|c|c|c|}
\hline \multirow[b]{2}{*}{ Subject } & \multicolumn{5}{|c|}{ Nominal Compression Ratio $\left(\frac{\%}{0}\right)$} \\
\hline & 45 & 55 & 65 & 70 & 75 \\
\hline 1. & $\overline{94}$ & 78 & 62 & $\overline{44}$ & 30 \\
\hline 2 . & 92 & 92 & 78 & 54 & 36 \\
\hline 3. & 94 & 90 & 62 & 52 & 24 \\
\hline 4 . & 98 & 90 & 84 & 74 & 46 \\
\hline 5. & 86 & 88 & 68 & 38 & 18 \\
\hline 6. & 98 & 80 & 78 & 66 & 20 \\
\hline 7. & 90 & 90 & 54 & 52 & 18 \\
\hline 8. & 88 & 84 & 72 & 42 & 10 \\
\hline 9. & 86 & 78 & 72 & 62 & 28 \\
\hline 10. & 92 & 86 & 72 & 54 & 12 \\
\hline 11. & 98 & 90 & 80 & 70 & 34 \\
\hline 12. & 96 & 92 & 80 & 48 & 26 \\
\hline 13. & 88 & 82 & 60 & 40 & 18 \\
\hline 14. & 90 & 84 & 70 & 34 & 28 \\
\hline 15. & 90 & 86 & 76 & 54 & 38 \\
\hline 16. & 90 & 88 & 82 & 56 & 44 \\
\hline MEAN & 91.9 & 86.1 & 71.9 & 52.5 & 26 \\
\hline ST DEV & 4.1 & 4.7 & 8.8 & 11.5 & 10 \\
\hline MIN & 86 & 78 & 54 & 34 & 10 \\
\hline MAX & 98 & 92 & 84 & 74 & 46 \\
\hline RANGE & 12 & 14 & 30 & 40 & 36 \\
\hline
\end{tabular}


Appendix D

The Individual Subject correct Recognition Scores (in Percent Correct) for the Five Presentation Levels of the 45\% Compression Condition ( $C$ in the order column) for Experiment II.

\begin{tabular}{|c|c|c|c|c|c|c|}
\hline \multirow{2}{*}{ Subject } & \multirow{3}{*}{ Order } & \multicolumn{6}{|c|}{ Presentation Level (dB SPL) } \\
\cline { 2 - 7 } & 30 & 40 & 50 & 60 & 70 \\
\hline \hline I. & ABC & 2 & 48 & 80 & 88 & 96 \\
2. & ACB & 6 & 30 & 68 & 86 & 88 \\
3. & BAC & 12 & 42 & 76 & 90 & 94 \\
4. & BCA & 2 & 30 & 60 & 72 & 84 \\
5. & CAB & 6 & 26 & 60 & 84 & 92 \\
6. & CBA & 4 & 34 & 74 & 90 & 96 \\
7. & ABC & 0 & 2 & 26 & 54 & 78 \\
8. & ACB & 6 & 40 & 86 & 84 & 98 \\
9. & BAC & 12 & 40 & 68 & 84 & 92 \\
10. & BCA & 4 & 38 & 66 & 88 & 94 \\
11. & CAB & 8 & 44 & 82 & 84 & 96 \\
12. & CBA & 2 & 28 & 68 & 80 & 92 \\
13. & ABC & 8 & 38 & 60 & 72 & 92 \\
14. & ACB & 2 & 38 & 66 & 94 & 86 \\
15. & BAC & 10 & 54 & 86 & 88 & 98 \\
16. & BCA & 2 & 26 & 60 & 74 & 92 \\
17. & CAB & 2 & 54 & 78 & 88 & 96 \\
18. & CBA & 0 & 16 & 56 & 80 & 94 \\
& & & & & & \\
& Mean & 4.9 & 34.9 & 67.8 & 82.2 & 92.1 \\
& STD & 3.8 & 12.9 & 14.1 & 9.4 & 5.2 \\
& Min & 0 & 2 & 26 & 54 & 78 \\
& Max & 12 & 54 & 86 & 94 & 98 \\
& Range & 12 & 52 & 60 & 40 & 20 \\
\hline
\end{tabular}


Appendix D Cont.

The Individual Subject Correct Recognition Scores (in Percent Correct) for the Five Presentation Levels of the 65\% Compression Condition ( $B$ in the order column) for Experiment II.

\begin{tabular}{|c|c|c|c|c|c|c|}
\hline \multirow{2}{*}{ Subject } & \multirow{3}{*}{} & \multicolumn{6}{|c|}{ Presentation Level (dB SPL) } \\
\cline { 2 - 7 } & Order & 35 & 45 & 55 & 65 & 75 \\
\hline \hline 1. & ABC & 4 & 16 & 52 & 68 & 56 \\
2. & ACB & 8 & 36 & 66 & 74 & 74 \\
3. & BAC & 6 & 44 & 62 & 68 & 80 \\
4. & BCA & 0 & 14 & 40 & 54 & 48 \\
5. & CAB & 8 & 28 & 54 & 62 & 82 \\
6. & CBA & 10 & 44 & 76 & 90 & 92 \\
7. & ABC & 0 & 2 & 32 & 44 & 48 \\
8. & ACB & 14 & 56 & 58 & 76 & 86 \\
9. & BAC & 16 & 36 & 52 & 72 & 68 \\
10. & BCA & 0 & 16 & 64 & 70 & 70 \\
11. & CAB & 10 & 54 & 66 & 80 & 86 \\
12. & CBA & 8 & 34 & 72 & 72 & 90 \\
13. & ABC & 4 & 28 & 72 & 78 & 66 \\
14. & ACB & 8 & 58 & 78 & 80 & 88 \\
15. & BAC & 4 & 38 & 36 & 68 & 68 \\
16. & BCA & 0 & 12 & 48 & 58 & 66 \\
17. & CAB & 6 & 44 & 70 & 90 & 76 \\
18. & CBA & 0 & 14 & 40 & 78 & 78 \\
& & & & & & \\
& Mean & 5.9 & 31.9 & 57.7 & 71.2 & 73.4 \\
& STD & 4.9 & 16.7 & 14.2 & 11.7 & 13.4 \\
& Min & 0 & 2 & 32 & 44 & 48 \\
& Max & 16 & 58 & 78 & 90 & 92 \\
& Range & 16 & 56 & 46 & 46 & 44 \\
\hline
\end{tabular}


Appendix D Cont.

The Individual Subject Correct Recognition Scores (in Percent Correct) for the Five Presentation Levels of the $75 \%$ compression condition ( $A$ in the order Column) for Experiment II.

\begin{tabular}{|c|c|c|c|c|c|c|}
\hline \multirow[b]{2}{*}{ Subject } & \multirow[b]{2}{*}{ Order } & \multicolumn{5}{|c|}{ Presentation Level (aB SPL) } \\
\hline & & 50 & 60 & 70 & 80 & 90 \\
\hline 1 & $\mathrm{ABC}$ & 8 & 12 & 28 & 20 & 22 \\
\hline 2 . & $\mathrm{ACB}$ & 0 & 4 & 26 & 38 & 36 \\
\hline 3. & BAC & 22 & 42 & 48 & 54 & 22 \\
\hline 4. & $\mathrm{BCA}$ & 18 & 38 & 42 & 42 & 54 \\
\hline 5 . & $\mathrm{CAB}$ & 36 & 34 & 38 & 42 & 36 \\
\hline 6. & CBA & 42 & 66 & 72 & 72 & 52 \\
\hline 7 . & $A B C$ & 2 & 2 & 30 & 30 & 26 \\
\hline 8 . & $A C B$ & 12 & 24 & 40 & 46 & 46 \\
\hline 9. & BAC & 30 & 48 & 52 & 46 & 30 \\
\hline 10. & $B C A$ & 30 & 42 & 58 & 50 & 54 \\
\hline 11. & $C A B$ & 26 & 40 & 50 & 50 & 46 \\
\hline 12. & $\mathrm{CBA}$ & 22 & 52 & 64 & 72 & 50 \\
\hline 13. & $A B C$ & 0 & 16 & 48 & 36 & 28 \\
\hline 14. & $A C B$ & 10 & 14 & 44 & 54 & 50 \\
\hline 15. & BAC & 18 & 60 & 58 & 62 & 30 \\
\hline 16. & $B C A$ & 28 & 46 & 50 & 60 & 46 \\
\hline 17. & $\mathrm{CAB}$ & 30 & 48 & 48 & 58 & 54 \\
\hline 18. & $C B A$ & 16 & 34 & 54 & 52 & 46 \\
\hline & Mean & 19.4 & 34.6 & 47.2 & 49.1 & 40.4 \\
\hline & STD & 12.4 & 18.7 & 12.1 & 13.5 & 11.6 \\
\hline & Min & 0 & 2 & 26 & 20 & 22 \\
\hline & $\operatorname{Max}$ & 42 & 66 & 72 & 72 & 54 \\
\hline & Range & 42 & 64 & 46 & 52 & 32 \\
\hline
\end{tabular}


Appendix E

Percent of Subjects who Correctly Recognized the Target words (NU No.6, List 1) for each of the Five Compression Ratios.

\begin{tabular}{|c|c|c|c|c|c|c|}
\hline & \multirow[b]{2}{*}{ Word } & \multicolumn{5}{|c|}{ Compression Ratio } \\
\hline & & 458 & 558 & 658 & 708 & 758 \\
\hline 1. & laud & 93.8 & 68.8 & 93.8 & 68.8 & 0.0 \\
\hline 2 . & boat & 93.8 & 100.0 & 50.0 & 18.8 & 31.3 \\
\hline 3. & pool & 100.0 & 100.0 & 93.8 & 93.8 & 18.8 \\
\hline 4. & nag & 100.0 & 87.5 & 62.5 & 0.0 & 6.3 \\
\hline 5 . & $1 \mathrm{imb}$ & 100.0 & 87.5 & 87.5 & 37.5 & 37.5 \\
\hline 6. & shout & 100.0 & 100.0 & 87.5 & 62.5 & 31.3 \\
\hline 7. & sub & 100.0 & 93.8 & 62.5 & 6.3 & 31.3 \\
\hline 8. & vine & 100.0 & 87.5 & 56.3 & 87.5 & 18.8 \\
\hline 9. & dime & 100.0 & 81.3 & 62.5 & 18.8 & 18.8 \\
\hline 10. & goose & 81.3 & 93.8 & 100.0 & 25.0 & 6.3 \\
\hline 11. & whip & 100.0 & 62.5 & 100.0 & 81.3 & 0.0 \\
\hline 12. & tough & 100.0 & 100.0 & 43.8 & 6.3 & 87.5 \\
\hline 13. & puff & 100.0 & 100.0 & 0.0 & 56.3 & 18.8 \\
\hline 14. & keen & 75.0 & 93.8 & 75.0 & 56.3 & 6.3 \\
\hline 15. & death & 75.0 & 43.8 & 81.3 & 18.8 & 0.0 \\
\hline 16. & seli & 31.3 & 81.3 & 68.8 & 93.8 & 0.0 \\
\hline 17. & take & 43.8 & 100.0 & 62.5 & 68.8 & 31.3 \\
\hline 18. & fall & 75.0 & 93.8 & 62.5 & 56.3 & 43.8 \\
\hline 19. & raise & 87.5 & 31.3 & 68.8 & 18.8 & 0.0 \\
\hline 20. & third & 100.0 & 81.3 & 68.8 & 75.0 & 6.3 \\
\hline 21. & gap & 93.8 & 100.0 & 62.5 & 37.5 & 0.0 \\
\hline 22 . & fat & 100.0 & 93.8 & 100.0 & 56.3 & 25.0 \\
\hline 23. & met & 93.8 & 75.0 & 93.8 & 56.3 & 0.0 \\
\hline 24. & jar & 87.5 & 93.8 & 93.8 & 43.8 & 31.3 \\
\hline 25. & door & 100.0 & 12.5 & 87.5 & 50.0 & 50.0 \\
\hline 26. & love & 93.8 & 87.5 & 25.0 & 43.8 & 6.3 \\
\hline 27. & sure & 100.0 & 75.0 & 93.8 & 43.8 & 25.0 \\
\hline 28. & knock & 87.5 & 93.8 & 93.8 & 62.5 & 6.3 \\
\hline 29. & choice & 100.0 & 62.5 & 18.8 & 62.5 & 12.5 \\
\hline 30. & hash & 93.8 & 100.0 & 56.3 & 12.5 & 12.5 \\
\hline 31. & lot & 100.0 & 100.0 & 25.0 & 18.8 & 6.3 \\
\hline 32. & raid & 93.8 & 93.8 & 93.8 & 62.5 & 0.0 \\
\hline 33. & hurl & 87.5 & 93.8 & 87.5 & 31.3 & 56.3 \\
\hline 34. & moon & 100.0 & 100.0 & 43.8 & 37.5 & 68.8 \\
\hline 35. & page & 100.0 & 100.0 & 43.8 & 93.8 & 25.0 \\
\hline 36. & yes & 100.0 & 100.0 & 87.5 & 37.5 & 0.0 \\
\hline 37. & reach & 100.0 & 87.5 & 93.8 & 93.8 & 18.8 \\
\hline 38. & king & 81.3 & 93.8 & 100.0 & 0.0 & 0.0 \\
\hline 39. & home & 100.0 & 93.8 & 62.5 & 25.0 & 6.3 \\
\hline 40. & rag & 81.3 & 50.0 & 12.5 & 75.0 & 31.3 \\
\hline 41. & which & 93.8 & 100.0 & 12.5 & 31.3 & 31.3 \\
\hline 42. & week-weak & 87.5 & 68.8 & 68.8 & 43.8 & 75.0 \\
\hline 43. & size & 31.3 & 56.3 & 81.3 & 87.5 & 0.0 \\
\hline 44. & mode & 100.0 & 68.8 & 93.8 & 37.5 & 50.0 \\
\hline 45. & bean & 100.0 & 56.3 & 81.3 & 37.5 & 75.0 \\
\hline 46. & tip & 81.3 & 100.0 & 93.8 & 100.0 & 6.3 \\
\hline 47. & chalk & 56.3 & 100.0 & 43.8 & 87.5 & 0.0 \\
\hline 48. & jail & 87.5 & 93.8 & 37.5 & 37.5 & 43.8 \\
\hline 49. & burn & 81.3 & 50.0 & 75.0 & 93.8 & 6.3 \\
\hline 50. & kite & 68.8 & 100.0 & 100.0 & 31.3 & 50.0 \\
\hline
\end{tabular}


Appendix E Cont.

Percent of Subjects who Correctly Recognized the Target words (NU No.6, List 4) for each of the Five Compression Ratios.

\begin{tabular}{|c|c|c|c|c|c|c|}
\hline & \multirow[b]{2}{*}{ Word } & \multicolumn{5}{|c|}{ Compression Ratio } \\
\hline & & 458 & 558 & 658 & 708 & 758 \\
\hline 1 . & pass & 100.0 & 18.8 & 100.0 & 100.0 & 37.5 \\
\hline 2 . & doll & 100.0 & 100.0 & 81.3 & 56.3 & 50.0 \\
\hline 3. & back & 100.0 & 93.8 & 100.0 & 87.5 & 75.0 \\
\hline 4. & red & 100.0 & 100.0 & 87.5 & 43.8 & 0.0 \\
\hline 5. & wash & 100.0 & 75.0 & 100.0 & 93.8 & 81.3 \\
\hline 6. & sour & 87.5 & 75.0 & 93.8 & 75.0 & 37.5 \\
\hline 7. & bone & 93.8 & 87.5 & 93.8 & 50.0 & 18.8 \\
\hline 8. & get & 100.0 & 100.0 & 93.8 & 37.5 & 18.8 \\
\hline 9. & wheat & 87.5 & 68.8 & 100.0 & 62.5 & 25.0 \\
\hline 10. & thumb & 100.0 & 100.0 & 93.8 & 37.5 & 6.3 \\
\hline 11. & sail-sale & 93.8 & 68.8 & 68.8 & 68.8 & 81.3 \\
\hline 12. & yearn & 62.5 & 93.8 & 56.3 & 18.8 & 0.0 \\
\hline 13. & wife & 100.0 & 87.5 & 75.0 & 56.3 & 31.3 \\
\hline 14. & such & 100.0 & 100.0 & 93.8 & 93.8 & 62.5 \\
\hline 15. & neat & 100.0 & 100.0 & 87.5 & 62.5 & 25.0 \\
\hline 16. & peg & 100.0 & 100.0 & 68.8 & 12.5 & 6.3 \\
\hline 17. & $\mathrm{mob}$ & 100.0 & 81.3 & 12.5 & 6.3 & 0.0 \\
\hline 18. & gas & 100.0 & 93.8 & 56.3 & 31.3 & 6.3 \\
\hline 19. & check & 100.0 & 100.0 & 93.8 & 93.8 & 18.8 \\
\hline 20. & join & 100.0 & 93.8 & 37.5 & 6.3 & 0.0 \\
\hline 21. & lease & 100.0 & 93.8 & 87.5 & 75.0 & 18.8 \\
\hline 22. & long & 100.0 & 87.5 & 43.8 & 37.5 & 37.5 \\
\hline 23. & chain & 87.5 & 87.5 & 31.3 & 25.0 & 50.0 \\
\hline 24. & kill & 93.8 & 100.0 & 93.8 & 68.8 & 31.3 \\
\hline 25 & hole-whole & 100.0 & 68.8 & 68.8 & 50.0 & 6.3 \\
\hline 26. & lean & 100.0 & 68.8 & 68.8 & 6.3 & 0.0 \\
\hline 27. & tape & 50.0 & 100.0 & 18.8 & 37.5 & 31.3 \\
\hline 28. & tire & 93.8 & 87.5 & 100.0 & 100.0 & 50.0 \\
\hline 29. & dip & 93.8 & 100.0 & 62.5 & 18.8 & 18.8 \\
\hline 30. & rose & 75.0 & 43.8 & 81.3 & 31.3 & 6.3 \\
\hline 31. & came & 100.0 & 87.5 & 37.5 & 12.5 & 18.8 \\
\hline 32. & fit & 75.0 & 56.3 & 100.0 & 100.0 & 18.8 \\
\hline 33. & make & 100.0 & 75.0 & 100.0 & 68.8 & 12.5 \\
\hline 34 & vote & 93.8 & 100.0 & 37.5 & 43.8 & 6.3 \\
\hline 35 & judge & 93.8 & 100.0 & 100.0 & 93.8 & 93.8 \\
\hline 36 & food & 100.0 & 56.3 & 93.8 & 87.5 & 68.8 \\
\hline 37. & ripe & 81.3 & 100.0 & 18.8 & 0.0 & 0.0 \\
\hline 38. & have & 100.0 & 81.3 & 62.5 & 25.0 & 0.0 \\
\hline 39. & rough & 81.3 & 100.0 & 37.5 & 37.5 & 12.5 \\
\hline 40 & kick & 100.0 & 100.0 & 75.0 & 31.3 & 6.3 \\
\hline 41 & lose & 87.5 & 93.8 & 87.5 & 56.3 & 31.3 \\
\hline 42 & near & 100.0 & 87.5 & 100.0 & 75.0 & 37.5 \\
\hline 43 & perch & 93.8 & 87.5 & 75.0 & 87.5 & 25.0 \\
\hline 44 & shirt & 93.8 & 93.8 & 87.5 & 87.5 & 81.3 \\
\hline 45 & bath & 93.8 & 100.0 & 56.3 & 6.3 & 6.3 \\
\hline 46 & time & 87.5 & 93.8 & 12.5 & 25.0 & 6.3 \\
\hline 47 & hall & 100.0 & 93.8 & 68.8 & 56.3 & 25.0 \\
\hline 48 & mood & 87.5 & 75.0 & 56.3 & 81.3 & 6.3 \\
\hline 49 & $\operatorname{dog}$ & 37.5 & 68.8 & 100.0 & 81.3 & 62.5 \\
\hline 50 & should & 68.8 & 81.3 & 37.5 & 25.0 & 0.0 \\
\hline
\end{tabular}

